\title{
Surface complexation modeling of arsenic mobilization from goethite: Interpretation of an in-situ experiment
}

Stolze, Lucien; Zhang, Di; Guo, Huaming; Rolle, Massimo

Published in:

Geochimica et Cosmochimica Acta

Link to article, DOI:

10.1016/j.gca.2019.01.008

Publication date:

2019

Document Version

Peer reviewed version

Link back to DTU Orbit

Citation (APA):

Stolze, L., Zhang, D., Guo, H., \& Rolle, M. (2019). Surface complexation modeling of arsenic mobilization from goethite: Interpretation of an in-situ experiment. Geochimica et Cosmochimica Acta, 248, 274-288.

https://doi.org/10.1016/j.gca.2019.01.008

\section{General rights}

Copyright and moral rights for the publications made accessible in the public portal are retained by the authors and/or other copyright owners and it is a condition of accessing publications that users recognise and abide by the legal requirements associated with these rights.

- Users may download and print one copy of any publication from the public portal for the purpose of private study or research.

- You may not further distribute the material or use it for any profit-making activity or commercial gain

- You may freely distribute the URL identifying the publication in the public portal 
This is a Post Print of the article published on line $11^{\text {th }}$ January 2019 in Geochimica et Cosmochimica Acta. The publishers' version is available at the permanent link: https://doi.org/10.1016/j.gca.2019.01.008

\title{
Surface complexation modeling of arsenic
} mobilization from goethite: Interpretation of an in-situ experiment

\author{
Lucien Stolze ${ }^{1}$, Di Zhang ${ }^{2}$, Huaming Guo ${ }^{2}$, and Massimo Rolle ${ }^{1, *}$ \\ ${ }^{1}$ Department of Environmental Engineering, Technical University of Denmark, \\ Bygningstorvet, Building 115, 2800 Kgs. Lyngby, Denmark \\ ${ }^{2}$ School of Water Resources and Environment, China University of Geosciences, \\ Beijing 100083, China \\ *Corresponding author phone: +45 45251566; email: masro@env.dtu.dk
}

\section{Highlights}

- Surface complexation modeling of the As release from goethite in groundwater

- One set of SCM parameters allowed modeling the measured As concentration in 7 wells

- The CD-MUSIC model performs better than the DDL under natural hydrochemical conditions

- As desorption rate and extent non-linearly controlled by many aqueous species

- Sensitivity analysis highlighted the key controls of $\mathrm{pH}, \mathrm{PO}_{4}^{3-}$ and $\mathrm{Ca}^{2+}$ on $\mathrm{As}$ sorption 


\section{ABSTRACT}

2 Sorption has been recognized as a predominant process for the mobility and transport of

3 arsenic (As) in groundwater. However, the model-based description of the chemical and

4 physical mechanisms controlling As interaction with mineral surfaces under natural

5 hydrochemical conditions remains a formidable challenge. In this study we assess and

6 compare the ability of existing surface complexation models (SCMs), the diffuse double

7 layer model (DDL) and the charge distribution multisite complexation model (CD-

8 MUSIC), to simulate As desorption from goethite in groundwater. We consider the

9 outcomes of an in-situ experiment recently performed in an arsenic-contaminated aquifer

10 of Northern China where As-loaded goethite-coated sand was deployed in 7 monitoring

11 wells. Determination and measurements of As-surface species were carried out over a

12 time period of 80 days in all monitoring wells. Simultaneous calibration of the models

13 with the measurements in the 7 wells was performed to obtain single sets of surface

14 complexation parameters for the DDL and the CD-MUSIC models, respectively.

15 Although the general dynamic pattern of the As release at the site is captured by both

16 models, the approach based on the CD-MUSIC agrees best with the field experimental

17 data without modifications of the surface complexation database compiled from previous

18 studies on goethite. Conversely, calibration of the DDL affinity constants led to

19 substantial improvement in the agreement between model simulations and the considered

20 field dataset.

21 The model outcomes and the exploration of the sensitivity of the goethite surface

22 composition to changes in hydrochemical conditions provide insights into the

23 mechanisms controlling arsenic sorption and their different description in the DDL and 
24 the CD-MUSIC models. Both SCMs indicate that $\mathrm{PO}_{4}^{3-}$ acts as the main competitor for $25 \mathrm{As}(\mathrm{V})$ sorption sites, and that $\mathrm{Fe}(\mathrm{II})$ does not have a significant effect on the As(V)

26 release despite its strong affinity for the goethite surface. Neither SCM suggests direct

27 binding of As(III) to goethite. However, the CD-MUSIC model predicts significant 28 formation of a goethite-Fe(II)-As(III) complex under the mildly alkaline conditions of the 29 groundwater at the field site and that such complex is insensitive to phosphate

30 competition. The CD-MUSIC implementation also allows capturing the non-linear charge

31 effects of the major ions, including $\mathrm{Ca}^{2+}$ and $\mathrm{Mg}^{2+}$, which appear to have important

32 implication in the mechanisms of As sorption at the field site.

\section{1. Introduction}

34 Arsenic (As) geogenic contamination of groundwater represents a global threat to the

35 health of millions of people in different parts of the World (Smedley and Kinniburgh,

36 2002; Polizzotto et al., 2008; Bretzler et al., 2018). This severe environmental problem

37 has been extensively studied in South East Asia as, for example, in the Mekong, Red

38 River and Bengal Deltas (Postma et al., 2007; Jessen et al., 2012; Lowers et al., 2007;

39 Berg et al., 2008; Biswas et al., 2014; Postma et al., 2012; Kulkarni et al., 2017).

40 Although less extensively investigated, arsenic contamination in groundwater has also

41 been reported in several sedimentary basins in Northern China (Guo et al., 2014; Guo et

42 al., 2008; Rodríguez-lado et al., 2013). In regions with arsenic contaminated aquifers, the

43 drilling of drinking water wells, the planning of groundwater pumping for irrigation

44 (Benner and Fendorf, 2010), and the design of mitigation strategies such as in-situ

45 remediation (Sun et al., 2018) require the assessment of arsenic spatial and temporal 46 occurrence. Thus, it is of primary importance to understand the processes governing the 
47 release and mobility of arsenic. Over the last decades, there has been growing

48 understanding of the fundamental role of iron (hydr)oxides for the fate and mobility of

49 heavy metals through co-occurring dissolution, precipitation and transformation

50 processes resulting in the release and/or incorporation of the contaminant into the

51 structure of iron minerals (Johannesson and Neumann, 2013; Pedersen et al., 2006;

52 Tufano and Fendorf, 2008; Kocar et al., 2010). In particular, Fe-oxides can effectively

53 immobilize As through sorption processes due to their large surface areas and their

54 charged reactive surface sites that provide one of the highest sorption capacity among soil

55 minerals (Dixit and Hering, 2003; Stachowicz et al., 2006; Gustafsson and Bhattacharya,

56 2007; Smedley and Kinniburgh, 2002). Goethite is of particular interest due to its stability

57 and its abundance in the subsurface (Cornell and Schwertmann, 2003; Pedersen et al.,

58 2006; Johannesson and Neumann, 2013). The affinity of As for iron (hydr)oxides surface

59 sites depends on the oxidation state of As, the mineralogy of Fe-oxides, the $\mathrm{pH}$ and

60 aqueous charged species competing for sorption sites (Dixit and Hering, 2003;

61 Stachowicz et al., 2006; Stachowicz et al., 2008). The interaction between arsenic and

62 iron (hydr)oxides is of key importance for As mobility and transport in groundwater

63 systems.

64 Surface complexation models (SCMs) provide a mathematical description of the

65 surface/solution chemistry and of the competitive and synergic effects of ions adsorption

66 considering the influence of the chemical properties of the aqueous solution and of the

67 solids. In particular, these models consider the chemical bonding between the mineral

68 surface and species (i.e., complexation) and the electrostatic interactions between charged

69 surfaces and charged species (Hayes et al., 1990; Davis and Kent, 1990; Goldberg, 1992; 
70 Appelo and Postma, 2005). Surface complexation reactions databases are traditionally

71 implemented based on well-controlled laboratory experiments performed with a low

72 number of aqueous species (Hayes et al., 1990; Dixit and Hering, 2003; Dzombak and

73 Morel, 1990; Mathur and Dzombak, 2006). In contrast, model-based interpretation of As

74 sorption behavior in multi-sorbate systems remain challenging as the interactions

75 between aqueous charged species can be strong, resulting in a complex, nonlinear

76 sorption behavior (Stachowicz et al., 2008). For instance, Dixit and Hering (2006)

77 successfully modeled the sorption of As(III) and Fe(II) individually but had difficulties in

78 reproducing the observations in dual-adsorbates systems using the diffuse double layer

79 (DDL) model. Stachowicz et al. (2008) satisfactorily modeled the sorption of As, $\mathrm{Ca}^{2+}$,

$80 \mathrm{Mg}^{2+}, \mathrm{PO}_{4}^{3-}$ and $\mathrm{HCO}_{3}^{-}$in dual and triple adsorbate batch systems with the CD-MUSIC

81 model and determined a single set of surface complexation parameters from observations

82 of the individual species. These promising results, towards the implementation of SCMs

83 that can provide accurate predictions under variable hydrochemical conditions, stems

84 from the consideration of microscopic information (i.e., surface and complexes structure)

85 and electrostatic interaction between charged species at the mineral surface in the CD-

86 MUSIC model. A few studies performed evaluations of field datasets by using the

87 ferrihydrite DDL and goethite CD-MUSIC models to estimate the competitive sorption

88 processes taking place on sediments of As contaminated aquifers (Jessen et al., 2012,

89 Biswas et al., 2014). However, the applicability of SCMs with surface complexation

90 constants typically determined from observations on single-sorbate systems to simulate

91 sorption on pure mineral phases in groundwater aquifers involving complex

92 hydrochemistry as well as flow conditions has not been rigorously tested. Therefore, 
93 studies with an intermediate level of complexity are of importance to understand the

94 complex coupling between surface and solution chemistry, electrostatic interactions and

95 mass transfer processes in groundwater systems, and to assess the ability and limitations

96 of SCMs. Such studies include controlled flow-through laboratory experiments (e.g.,

97 Tufano and Fendorf, 2008; Sharma et al., 2011; Muniruzzaman et al., 2014; Li et al.,

98 2014) as well as pilot scale field experiments (Neidhardt et al., 2014; Rawson et al., 2017,

99 Zhang et al., 2017).

100 In this study we consider the in-situ experiments performed by Zhang et al. (2017) in an

101 As-contaminated aquifer in a sedimentary basin in which the arsenic release from

102 synthetized As-loaded goethite-coated sand was investigated. The results of these

103 experiments suggested that the monitored As release was primarily driven by sorption

104 processes over the 80 days experimental period. Such recently published dataset offers a

105 unique opportunity to test the ability of the DDL and CD-MUSIC models to simulate

106 arsenic sorption under natural hydrochemical and flow-through conditions with sets of

107 surface reactions and affinity constants implemented based on the outcomes of

108 independent batch experiment studies. These SCMs were chosen based on their extensive

109 list of surface reactions for goethite as well as their broad application. To simulate As

110 desorption from the 7 observation wells at the field site we propose a flow-through

111 approach implementing the description of adsorption mechanisms in a complex

112 multicomponent system based on the DDL and CD-MUSIC models. We assess the

113 performance of the two models to reproduce the observed transient decrease and the

114 steady-state of As surface concentrations together with their respective predictions of the

115 change in surface composition. Sensitivity analyses were performed to compare the 
116 description of sorption mechanisms in the respective models as well as to strengthen our

117 understanding of the complex interplay between sorption competition and electrostatic

118 interactions affecting the fate and transport of As in natural groundwater systems.

120 2. Materials and methods

\section{$121 \quad$ 2.1. In-situ experiments and data set description}

122 In-situ field experiments are important to help bridging the gap between controlled

123 laboratory experiments and field observations. For instance, the in-situ exposure of

124 known mineral phases allows establishing natural anoxic hydrochemical and flow-

125 through conditions that are representative of groundwater systems but experimentally

126 difficult to maintain in the laboratory. Detailed description of the in-situ experiments

127 considered in this study is given in Zhang et al. (2017). Here, we only outline the key

128 methods and results concerning the goethite dataset that is the focus of this investigation.

129 The in-situ experiments were conducted in 7 wells in an aquifer in the Hetao Basin, Inner

130 Mongolia, China. Geochemical investigations performed at this site revealed increasing

131 aqueous As concentration together with a change in the redox conditions from oxic to

132 reducing conditions in the direction of the groundwater flow from the Yin mountains to

133 the Yellow River's flat plain (Guo et al., 2010; Guo et al., 2016; Jia et al., 2014). The

134 wells used in the in-situ experiments are screened in the shallow sandy aquifer at depths

135 ranging from 8 to $30.6 \mathrm{~m}$ (Table EA1) in the area of slightly alkaline (i.e., $\mathrm{pH}$ [7.6 - 8.1])

136 and reducing conditions as well as high dissolved As concentrations (i.e., [1.98 - 606]

$137 \mathrm{ug} / \mathrm{L}$ ) with As(III) found as the predominant species ( 83\%). Chemical composition of 
138 the groundwater was measured three times in all wells during the in-situ experiments

139 (i.e., at 0,30 and 80 days) and the average groundwater composition is provided in Table $140 \quad$ EA2.

141 The goethite-coated sand was synthetized in the laboratory according to the method of 142 Schwertmann and Cornell (2000) and subsequently loaded with arsenate by immersing 143 the solid phase in a $500 \mathrm{mg} / \mathrm{L} \mathrm{As}(\mathrm{V})$ solution with a solid-to-solution ratio of $50 \mathrm{~g}$ coated 144 sand/L. The synthetized As-loaded goethite coated sand had a Fe content of $2.64 \mathrm{mg} / \mathrm{g}$ 145 dry coated sand, a bulk density of $2.6 \mathrm{~g} / \mathrm{cm}^{3}$ and a porosity of 0.5 (i.e., $21 \mathrm{~g}$ goethite/L) as 146 well as an As content of $31 \mu \mathrm{g} / \mathrm{g}$ dry coated sand. The coating of quartz sand with 147 goethite was confirmed by X-ray powder diffraction (XRD) together with scanning 148 electron microscopy (SEM). The As-loaded coated sand was divided into amounts of 0.5 $149 \mathrm{~g}$ which were wrapped in a permeable 100-mesh Teflon foil before being deployed and 150 hosted in 7 wells at screen depths (Table EA1) for approximately 80 days. A number of 151 such permeable foils containing the As-loaded goethite-coated sand were placed in each 152 well. In order to assess the transient change in iron mineral composition and As surface 153 concentration due to the flow of the natural groundwater through the goethite-coated 154 porous medium, the individual samples in the wells were collected at successive time 155 steps throughout the duration of the experiment. The total Fe and As contents of the As156 bearing goethite-coated sand were measured from two replicates by ICP-AES after total 157 digestion of $0.1 \mathrm{~g}$ dry sample using the microwave-assisted method of Link et al. (1998). 158 As K-edge X-Ray absorption (XANES) was applied to determine the As surface 159 oxidation state. The possibility that any potential iron mineral transformation took place 
160 during the in-situ experiments was investigated combining XRD, XANES and SEM

161 analyses (Zhang et al., 2017).

162 During the experiment, a progressive decrease of the As content in the goethite-coated

163 sand was observed in all monitoring wells as the reactive minerals deployed were flushed

164 by the natural groundwater flow. The analyses performed on the removed samples

165 showed that the total iron content remained the same throughout the experiment and no

166 Fe-oxides other than goethite were detected. Thus, no dissolution and/or transformation

167 of goethite occurred and competitive sorption/desorption mechanisms are the only cause

168 of arsenic release from goethite and As(V) was the only As species present on the

169 goethite at the end of the experiment $(t=80$ days $)$.

\section{$170 \quad$ 2.2. Geochemical modeling}

\section{$171 \quad$ 2.2.1. Modeling approach}

172 Modeling of As release from goethite through sorption competition is performed by

173 simulating the flow of groundwater through the deployed goethite-coated porous

174 medium. Such flow-through conditions lead to the continuous replenishment of dissolved

175 chemical constituents that contact the reactive mineral and cause a transient change in the

176 geochemical conditions and, thus, in the surface composition. Despite the reducing

177 conditions prevailing at the site, the reductive transformation of goethite was shown

178 insignificant by the iron mineral analyses confirming that goethite remained stable during

179 the in-situ experiments. Fig. 1 illustrates the conceptual framework used to simulate the

180 experimentally observed As release from goethite at the site.

181 The modeling approach can be summarized in the following steps: 
- Simulation of As loading onto goethite by equilibrating the goethite surface with the solution used in the laboratory to prepare the reactive samples of goethite-

184 coated sand deployed in the field.

185 - Definition of the groundwater solution according to the average hydrochemical 186 measurements at the field site (Table EA2).

187 - Simulation of the advective movement of groundwater through the goethite$188 \quad$ coated porous medium samples.

189 - Description of sorption/desorption in the flow-through setup assuming local 190 equilibrium and considering surface complexation reactions.

191 - Comparison between the simulated and measured As release from the goethite192 coated sand in the different wells.

193 - Exploration of possible improvement in the agreement with the field data when $194 \quad$ optimizing surface complexation parameters.

195 - Sensitivity analysis of surface composition and sorption mechanisms to 196 groundwater chemical composition. 


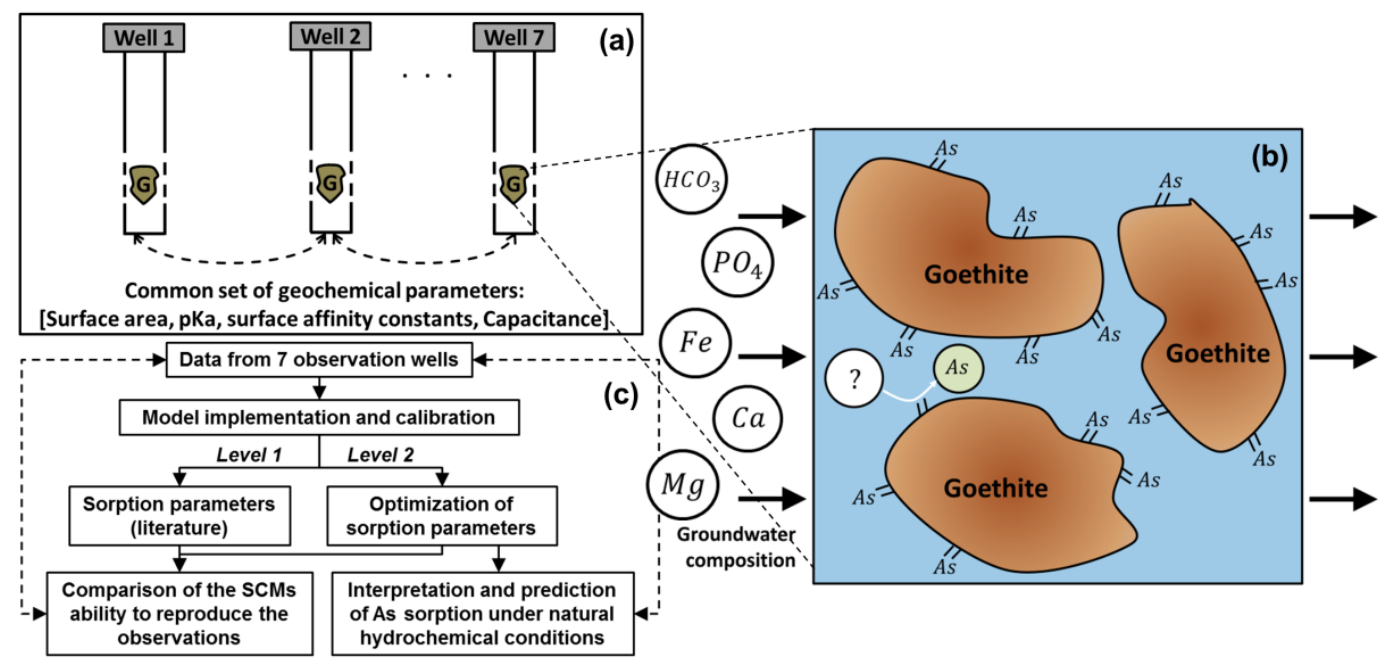

199 Fig. 1. Illustration of the modeling approach: (a) Sketch of the wells with the goethite

200 samples and parallel calibration of surface complexation parameters, (b) description of

201 solution and surface/solution processes under flow-through conditions, (c) flow chart

202 summarizing the model implementation strategy.

203 The modeling of the As pre-loading and subsequent desorption from goethite induced by

204 the flow-through conditions and the continuous supply of groundwater aqueous species

205 was implemented with the geochemical code PHREEQC-3 (Parkhurst and Appelo, 2013)

206 coupled with the software MATLAB $^{\circledR}$ using the IPhreeqc module (Charlton and

207 Parkhurst, 2011; Muniruzzaman and Rolle, 2016). Coupling these codes allowed us to

208 obtain a flexible simulation tool combining the transport and geochemical calculations

209 capabilities of PHREEQC with the computational methods of MATLAB ${ }^{\circledR}$ for

210 parallelizing the simulations, optimizing the set of model parameters, and for performing

211 sensitivity analyses (Haberer et al., 2015; Rolle et al., 2018). The thermodynamic

212 aqueous reactions database WATEQ4F was amended to include some key reactions that

213 might significantly influence the As mobility. In particular, we ensured thermodynamic 
214 consistency between the aqueous and surface complexation reactions defined for arsenic

215 by applying the set of As speciation reactions and constants used by Dixit and Hering 216 (2003) and Stachowicz et al. (2006, 2008). One protonation reaction for phosphate (Smith

217 and Martell, 1976) was added since this aqueous species can strongly influence the As 218 sorption (Dixit and Hering, 2003; see Table EA5 in the Electronic Annex). The flow rates 219 defined through the advective time steps were calibrated within a range of values 220 encompassing the groundwater flow conditions encountered at the field site ([0.01 - 1]

$221 \mathrm{~m} /$ day; Guo et al., 2016).

\section{2.2.2. Surface complexation}

223 The SCMs proposed in the literature mainly differ in their interfacial structures used to 224 mathematically describe the surface electrostatic field and its influence on the ions 225 present at the solid/solution interface; such ionic species interact electrostatically with the 226 surface of the mineral (Davis et al., 1978; Hayes and Leckie, 1987; Hayes et al., 1990;

227 Davis and Kent, 1990; Goldberg, 1992). In this study, we simulate the in-situ experiments 228 with the approach outlined in the previous section, implementing surface complexation 229 reactions according to the DDL and CD-MUSIC models.

230 The DDL model is composed of two layers, the surface and the diffuse double layer, to 231 account for (i) complexation reactions (i.e., formation of inner sphere complexes 232 chemically bound to the surface) and (ii) electrostatic interactions between the surface 233 and ions in the bulk solution. However, the DDL model doesn't explicitly account for the 234 position of charged species that electrostatically interact with the surface (i.e., treated as 235 point charges; Davis and Kent, 1990; Goldberg, 1992) whereas it has been shown that 
236 partially dehydrated ions might form ion-specific weak interactions with the surface

237 (Hayes and Leckie, 1987; Hiemstra and van Riemsdijk, 1996). To address this limitation

238 and improve the description of sorption mechanisms, the triple layer model was originally

239 proposed by Yates et al. (1974) and implemented by Davis et al. (1978) with the addition

240 of a Stern layer including two capacitances in-between the surface and the diffuse layer to

241 account for the outer-sphere complexes defined through mass law equations (Hayes and

242 Leckie, 1987; Davis and Kent, 1990; Rahnemaie et al., 2006). Following this extended

243 Stern model representation, the CD-MUSIC model developed by Hiemstra and van

244 Riemsdijk (1996) includes two additional components to describe macroscopic

245 adsorption mechanisms by considering spectroscopic and microscopic information on the

246 structures of the surface and the complexes. The multisite complexation (i.e., MUSIC)

247 component takes into account the coordination, the speciation, and the abundance of the

248 different types of surface functional groups having different affinity for charged species.

249 Furthermore, the concept of charge distribution (i.e., CD) is used to describe the charge

250 distribution of the surface complexes in the interfacial region due to the electrostatic

251 potential gradient that develops normal to the surface. The individual charges of the

252 adsorbed ions are distributed between different planes that delineate distinct layers at the

253 surface/solution interface. Different types of binding (e.g., monodentate, bidentate) are

254 explicitly considered in the CD-MUSIC model as the charge distribution of inner-sphere

255 complexes is derived from the geometry of the complexes through the Pauling bond

256 valence concept (Hiemstra and van Riemsdijk, 1996). The DDL model, instead, only

257 includes monodentate complexes. 
258 In the SCMs, the mineral surfaces are defined by the density of sites of the considered

259 surface groups, the specific surface area and the mass of the considered mineral. The site

260 densities were fixed to proposed literature values while the surface area was calibrated on

261 the experimentally observed transient As desorption. In the DDL model, a single type of

262 surface site for goethite is typically considered (Mathur and Dzombak, 2006). This

263 parameter was set to 2 sites $/ \mathrm{nm}^{2}$ for consistency with the As complexation reactions and

264 relative affinity constants that were determined by Dixit and Hering(2003). This value is

265 within the range of site densities reported in the literature $\left(1.4\right.$ sites $/ \mathrm{nm}^{2}$ Ali and

266 Dzombak, 1996; 2.3 sites/nm² van Geen et al., 1994). In the CD-MUSIC model, the

267 singly coordinated $\mathrm{FeOH}(\mathrm{H})$ and the triply coordinated $\mathrm{Fe}_{3} \mathrm{O}(\mathrm{H})$ surface groups of

268 goethite are considered with site densities fixed to 3.45 and 2.7 sites $/ \mathrm{nm}^{2}$, respectively,

269 for consistency with the CD-MUSIC surface reactions database (Hiemstra and van

270 Riemsdijk, 1996; Hiemstra and van Riemsdijk, 2006; Stachowicz et al., 2008). For both

271 SCMs, the surface area was calibrated within the range [40 - 110] $\mathrm{m}^{2} / \mathrm{g}$ based on previous

272 literature studies (Hiemstra and van Riemsdijk, 1996; Mathur and Dzombak, 2006).

273 Extensive surface reaction databases were implemented for the respective SCMs by

274 performing a literature review in order to model the complex geochemical behavior at the

275 surface/solution interface. The set of surface reactions for the DDL model consisted of a

276 series of protonation/deprotonation and complexation reactions with corresponding

277 affinity constants (Table EA3 in the Electronic Annex). The CD-MUSIC database

278 similarly contains surface reactions controlled by law of mass action equations but it 279 additionally allows the description of the charge distribution of a complex at the 280 surface/solution interface. This is done through the definition of charge allocation 
parameters among the 3 planes defined in the model (Table EA4 in the Electronic

282 Annex). The contributions of Stachowicz et al. (2006, 2007 and 2008) and Dixit and

283 Hering $(2003,2006)$ were considered as the base literature for the development of a

284 consistent database for goethite in the CD-MUSIC and DDL models, respectively. These

285 contributions were selected since they represent landmark studies assessing the As

286 sorption onto goethite in single and multi-sorbates aqueous systems. Additional surface

287 reactions and associated parameters were taken from previously published contributions

288 with consideration for thermodynamic consistency. The reader should refer to Tables

289 EA3 and EA4 in the Electronic Annex for a complete overview of the considered

290 references, surface complexation reactions and relative parameters used in the DDL and

291 CD-MUSIC models, respectively. We assessed the ability of the implemented SCM

292 parameters databases to simulate the As desorption by (i) applying the best estimates

293 proposed in individual publications and (ii) exploring the $95 \%$ confidence intervals to

294 improve the agreement with the data.

\section{$295 \quad$ 2.2.3. Calibration strategy and sensitivity analyses}

296 To explore possible improvement in reproducing the temporal release of arsenic from

297 goethite when optimizing the SCM parameters, the calibration of the CD-MUSIC and the

298 DDL was performed in two successive levels with different number of calibrated

299 parameters. The first calibration level (i.e., DDL 1 and CD-MUSIC 1) included only the

300 optimization of the flow rates and the goethite surface area. The second calibration level

301 (i.e., DDL 2 and CD-MUSIC 2) additionally comprised the surface complexation

302 parameters (i.e., affinity constants, capacitances, charge allocation coefficients) that were

303 allowed to vary within their confidence interval when reported in literature. The 
304 calibration of the sorption parameters was performed simultaneously by parallelizing the

305 simulations of the 7 different wells used in the field experiments (Fig. 1). All the goethite

306 used in the in-situ experiments and deployed in the different wells was synthetized in the

307 laboratory at the same time (Zhang et al., 2017) and, thus, was considered having

308 identical sorption properties in the simultaneous simulations (Fig. 1). The model

309 parameters were calibrated in the MATLAB ${ }^{\circledR}$ environment with an automated procedure

310 minimizing the root mean squared error (RMSE) between simulated and observed As

311 surface concentrations. Due to the high number of parameters and the non-linearity of the

312 problem, the heuristic, global-search particle swarm optimization (PSO) method was

313 chosen to minimize the objective function (Rathi et al., 2017; Rawson et al., 2016).

314 The mechanisms of sorption competition simulated using the selected SCMs are

315 functions of the aqueous solution composition of the natural groundwater, as well as, of

316 the surface complexation parameters. In order to make model-based interpretations of the

317 key hydrochemical factors controlling As sorption on goethite from calibrated models,

318 we address possible overfitting by fixing to their literature value the parameters that did

319 not lead to significant improvement in the agreement with the measured As surface

320 concentrations. The sensitivity of the goethite surface composition to changes in

321 hydrochemical conditions was tested using the optimized set of model parameters. In this

322 assessment, we performed batch and flow-through simulations of the goethite mineral

323 phase in contact with the groundwater for various aqueous compositions. The method of

324 Morris together with the radial point approach (Sohier et al., 2014) was applied in the

325 sensitivity analyses to test the direct and non-linear impact of the parameters on the

326 model output at low computational cost (Saltelli et al., 2004). Details about this method 
327 and on the design of the sensitivity analyses performed in this study are provided in

328 Section EA-4 in the Electronic Annex.

\section{3. Results}

\section{3.1. Arsenic desorption}

331 The field observations of As release from the synthetized goethite-coated sand were

332 simulated with the proposed modeling approach based on both the DDL and CD-MUSIC

333 descriptions of surface complexation reactions. Figure 2 illustrates the comparison

334 between the field measurements in the 7 different wells and the model simulations

335 obtained with the two calibration levels: without (i.e., level 1) and with (i.e., level 2)

336 optimization of the surface complexation constants (i.e., affinity constants, charge

337 allocation and capacitances).
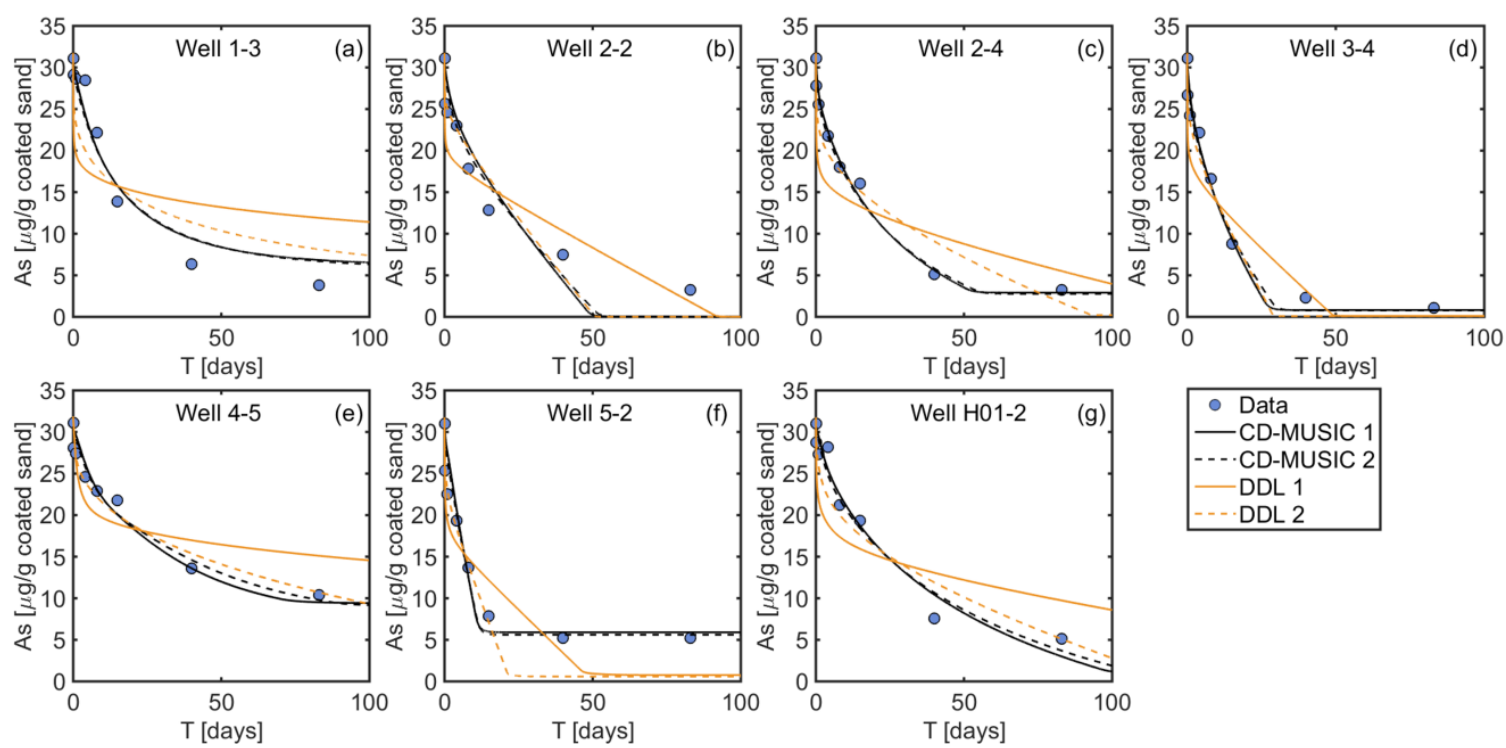

339 Fig. 2. Measured and simulated temporal change in adsorbed As concentrations in all

340 wells. Calibration level 1: SCM parameters fixed to the best estimate values reported in 
341 the literature; calibration level 2: SCM parameters calibrated within the respective range

342 of values reported in the literature.

343 The field datasets from the different wells show a transient release of As from goethite;

344 however, the extent of desorption evaluated at different times during the in-situ

345 experiment was found to be different and the decreasing trends of As concentrations on

346 the goethite-coated sand spatially differ as a combined result of the flow and aqueous

347 composition variability among the wells. A satisfying agreement between simulations and

348 observations is obtained using a single set of surface complexation parameters for all

349 observation wells using both the CD-MUSIC and the DDL formulations. Measurement of

350 the goodness-of-fit is provided in section EA-3 of the Electronic Annex. The best fit to

351 the measured As surface concentrations is achieved when using the CD-MUSIC to

352 describe the surface complexation reactions (Fig. 2). This model already provides a

353 satisfactory agreement with the experimental data at the calibration level 1 (i.e., directly

354 using literature values, without the need to calibrate the surface complexation

355 parameters). Successive calibration of these parameters (calibration level 2) only yielded

356 minor improvements (i.e., 3.7\% reduction of RMSE). In particular, the CD-MUSIC

357 reproduces best the temporal decrease in the extent of As desorption towards the steady-

358 state As surface concentrations observed in most of the wells (Fig. 2, Section EA-3). The

359 results of the DDL-based approach are different. The model with literature values for the

360 surface complexation parameters (calibration level 1) cannot capture the observed trends

361 in most of the observation wells (i.e., mean absolute relative error of 0.3, Hauduc et al.,

362 2015; continuous orange line in Fig. 2). A successive calibration step, optimizing the

363 surface complexation parameters, is necessary to obtain a significant improvement (i.e., 
$36434 \%$ reduction of RMSE) and a close representation of the observed As surface

365 concentration in all observation wells. This improvement resulted from the calibration of

366 three affinity constants, thus, the remaining constants were fixed to the best estimates

367 reported in the literature (Section EA-4). The optimized set of affinity constants for DDL

3682 is provided in Table EA3. Despite the apparent improvement, the calibrated DDL 2

369 model still cannot capture the leveling of As surface concentrations, approaching steady-

370 state conditions with the flowing groundwater, which was observed in most of the wells

371 at the end of the in-situ experiments (Fig. 2).

372 The calibrated values of flow rates (See Table EA7 in the Electronic Annex) and surface

373 areas $\left(49.6,45.8\right.$ and $43.6 \mathrm{~m}^{2} / \mathrm{g}$, respectively) were found consistent between the models:

374 CD-MUSIC 1, CD-MUSIC 2 and DDL 2, which provided the best representation of the

375 experimental observations, thus, allowing a direct comparison between the DDL and the

376 CD-MUSIC outcomes.

\section{3.2. Surface composition}

378 Once the model parameters were calibrated, the models were run in order to simulate the

379 temporal change in surface composition and to shed light on the surface competition

380 mechanisms affecting As desorption in the different wells. The temporal change in

381 surface composition was analyzed using the fractional site occupancy that expresses the

382 relative amount of sites occupied by a species.

383 Figure 3 displays the fractional site occupancy for all wells according to the calibrated 384 models at the initial time and at the end of the in-situ experiments ( 80 days). The models

385 selected are DDL 2 and CD-MUSIC 1, since further calibration of the latter did not result 
386 in significant improvements. The outcomes of the simulations show that the surface

387 compositions are similar among the locations of the observation wells at the field site for

388 a given SCM. Some similarities between the CD-MUSIC and the DDL models outcomes

389 can also be observed. For instance the strong affinity of phosphate ([40 - 50]\% and [23 -

$39038] \%$, respectively) and iron (30\% and [15 - 40]\% respectively) for goethite surface sites.

391 However, significant differences generally exist between the simulated surface

392 compositions when using the DDL and the CD-MUSIC approaches. In particular, the

393 DDL model shows significant sorption of $\mathrm{Mg}^{2+}$ (i.e., [15 - 33]\%) whereas the CD-

394 MUSIC shows a higher fraction of protonated sites (i.e., [6 - 9]\%). The DDL model also

395 shows minor adsorptions of $\mathrm{Ca}^{2+}$ and $\mathrm{HCO}_{3}^{-}$in wells $\mathrm{H} 01-2$ and 3-4, respectively, which

396 were not found significant in the simulations performed with the CD-MUSIC.

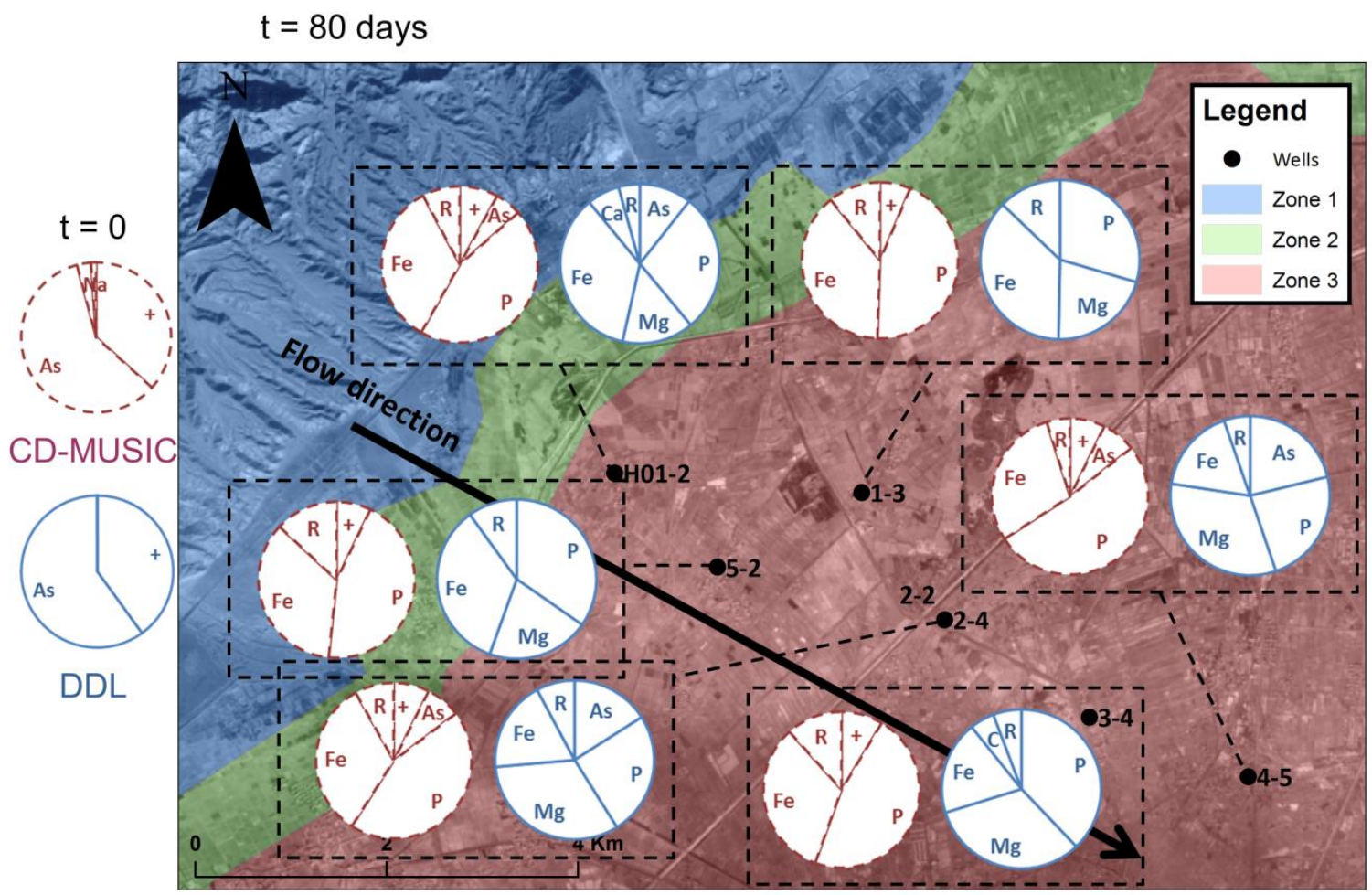


398 Fig. 3. Map of the field site with location of the observation wells and fractional site 399 occupancy at $\mathrm{t}=80$ days obtained with the CD-MUSIC (red) and DDL (blue). R is the 400 sum of all the remaining elements occupying less than $3 \%$ of the total sites. (+) and C 401 denote the protonated sites and sites occupied by carbonate species. Zones 1, 2 and 3 are 402 the areas of oxic, sub-oxic and reducing conditions identified at the field site (Jia et al., 403 2014).

404 Since the model results regarding species involved in sorption competition are similar 405 among the different wells for a given SCM, we focus on well 4-5 to assess further the 406 differences between SCM outcomes and the factors responsible for As desorption. The 407 simulation results for the remaining wells can be found in Section EA-3 in the Electronic 408 Annex. Figure 4 displays the dynamic change in surface composition in well 4-5 during 409 the field desorption experiments using the CD-MUSIC and the DDL models.
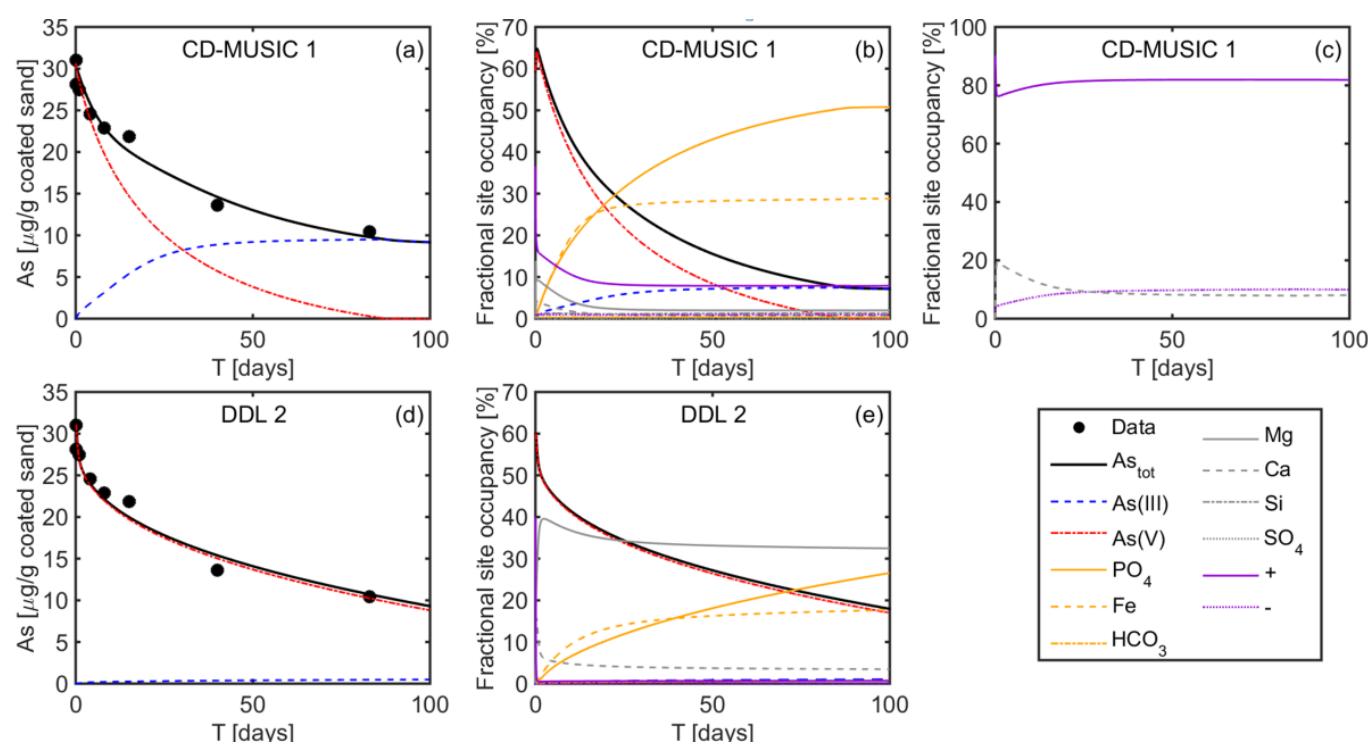

411 Fig. 4. Temporal change in surface composition of goethite in well 4-5. (a) and (d):

412 Change in As concentration and As speciation. (b) and (c): Change in fractional site 
413 occupancy of the singly and triply coordinated sites, respectively, for the CD-MUSIC.

414 (e): Change in fractional site occupancy of the surface sites for the DDL model. For the

415 CD-MUSIC model, protonated sites (+) were counted as $\equiv \mathrm{FeOH}_{2}^{+0.5}$ and $\equiv \mathrm{Fe}_{3} \mathrm{OH}^{+0.5}$, and

416 deprotonated sites (-) were counted as $\equiv \mathrm{FeOH}^{-0.5}$ and $\equiv \mathrm{Fe}_{3} \mathrm{O}^{-0.5}$. For the DDL model,

417 protonated and deprotonated sites were counted as $\mathrm{Goe}_{-} \mathrm{OH}_{2}^{+}$, $\mathrm{Goe}_{-} \mathrm{OH}^{-}$, respectively.

418 In the CD-MUSIC model results, As surface speciation consists both in As(III) and

$419 \mathrm{As}(\mathrm{V})$ with a decrease in $\mathrm{As}(\mathrm{V})$ surface concentration and an uptake of As(III) (Fig. 4a).

420 In contrast, the DDL model shows almost exclusively As(V) present on the surface (Fig.

421 4d). The adsorbed As(III) in the CD-MUSIC model mostly consists in the ternary

422 complex goethite-Fe(II)-As(III) accounting for more than $80 \%$ of the total adsorbed

423 As(III). The As adsorbed on the goethite surface is shown by the CD-MUSIC model to

424 exclusively remain as goethite-Fe(II)-As(III) complex at the end of the in-situ

425 experiments. However, spectroscopy analysis of the sampled material only revealed the

426 presence of $\mathrm{As}(\mathrm{V})$ at the surface of goethite (Zhang et al., 2017). To explain this

427 discrepancy, we hypothesize that surface oxidation of As(III) to As(V) occurred through

428 an electron transfer mechanism towards the bulk of the goethite. Such process has already

429 been observed under well-controlled laboratory conditions by Amstaetter et al. (2010)

430 and is likely to play an important role also under the hydrochemical conditions of the in-

431 situ experiment.

432 Regarding As(V) adsorbed onto goethite, both SCMs show an instantaneous change in 433 the surface speciation at initial time when goethite is incubated in the wells. In the CD-

434 MUSIC model, $\mathrm{As}(\mathrm{V})$ is equally shared between the bidentate $(\equiv \mathrm{FeO})_{2} \mathrm{AsO}_{2}^{-2}$ and the 
435 monodentate $\mathrm{FeOAsO}_{2} \mathrm{OH}^{-1.5}$ complexes when loaded onto goethite in the laboratory 436 whereas it consists mostly of $(\equiv \mathrm{FeO}){ }_{2} \mathrm{AsO}_{2}^{-2}$ (80 to $\left.90 \%\right)$ when put into contact with the 437 groundwater at the field site. In the DDL model, the surface speciation of As(V) changes 438 from $\mathrm{Goe}_{-} \mathrm{HAsO}_{4}^{-}$to $\mathrm{Goe}_{-} \mathrm{AsO}_{4}^{2-}$. The simulated speciation of surface complexes for 439 single species (i.e., As(V), phosphate, iron) is shown in Section EA-3 in the Electronic 440 Annex.

441 Both models show that the desorption of As is paralleled by the adsorption of phosphate 442 suggesting direct competition for the goethite sorption sites between these species. In 443 particular, the CD-MUSIC results show that steady-state is reached for these species at 444 about 80 days in well 4-5. The calculated surface speciation of phosphate with the CD445 MUSIC model shows that $(\equiv \mathrm{FeO})_{2} \mathrm{PO}_{2}^{2-}$ and $\equiv \mathrm{FeOPO} \mathrm{OH}^{-1.5}$ are present in quasi equal 446 proportions (i.e, [50-60]\% and [40-50]\%, respectively). The results of the DDL model 447 only show the phosphate surface species $\mathrm{GoePO}_{4}^{2-}$. Furthermore, the comparison between 448 the two models shows that the simulated site occupancy and surface concentration of 449 phosphate is significantly higher in the CD-MUSIC model (e.g., twice as much as in well $450 \quad 4-5)$.

451 Both models also show a significant and rapid change in surface composition when 452 bringing goethite in contact with the groundwater. The SCMs similarly result in a fast 453 uptake of $\mathrm{Fe}$ and a quasi-instantaneous decrease of protonated sites. Using the CD454 MUSIC approach, Fe sorbs onto goethite as two distinct surface species. The dominant 455 mechanism of iron uptake is the direct bond of Fe with the surface and formation of the 456 bidentate complex $(\equiv \mathrm{FeOH})_{2} \mathrm{Fe}^{+}$. This surface species is dominant $[50-90] \%$, however 
457 also the ternary monodentate complex involving arsenic and iron $\equiv \mathrm{FeAs}(\mathrm{OH})_{3} \mathrm{Fe}^{+0.5}$ is

458 present in significant proportion. Finally, both the CD-MUSIC and the DDL models

459 consistently result in sudden changes for deprotonation and magnesium uptake.

\section{$461 \quad 3.3$. Sensitivity analysis}

462 We present the results assessing the influence of changing hydrochemistry, from the base

463 case of natural groundwater composition measured at the site, on As affinity for goethite

464 surface. We analyze the impact of $\mathrm{pH}$ and trace compounds as well as major ions in two 465 distinct sections.

\section{3.3.1. Effects of pH and trace compounds}

467 We investigated the effects of $\mathrm{pH}, \mathrm{As}, \mathrm{PO}_{4}^{3-}$ and $\mathrm{Fe}$ on the simulated surface composition 468 for both SCMs as these aqueous species were shown to have the strongest affinity for the 469 goethite surface according to the modeling of the field As desorption experiments. A 470 series of batch calculations was performed, that consisted in modeling the change in 471 surface composition when varying, one at a time, $\mathrm{pH}$ and the concentrations of selected 472 trace compounds. Figure 5 displays the simulation results, using the groundwater 473 chemistry of well 4-5, and illustrates the individual influence of these aqueous species as 474 well as the non-linear behavior of the adsorption mechanisms computed by the DDL and 475 CD-MUSIC models. 


\section{CD-MUSIC}
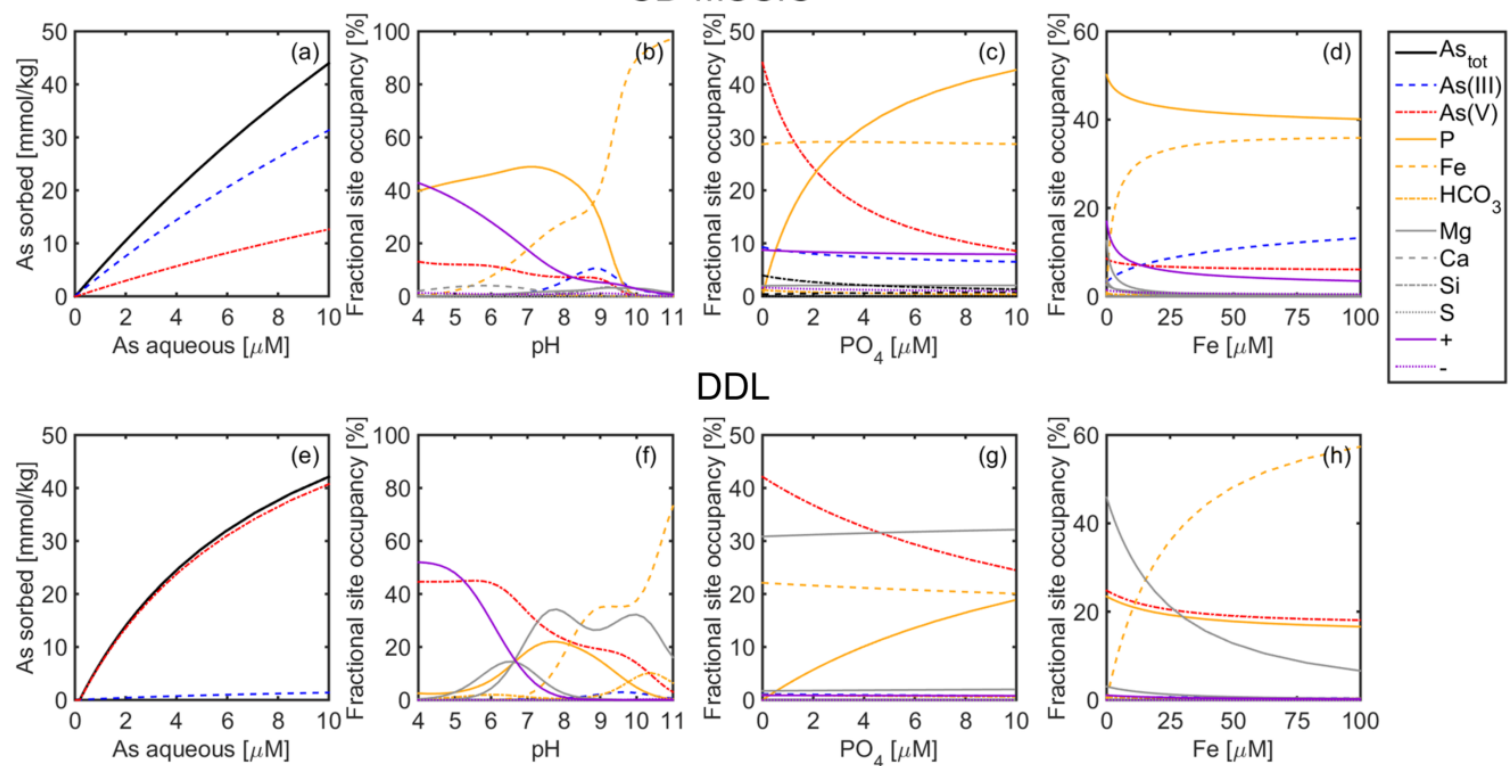

DDL
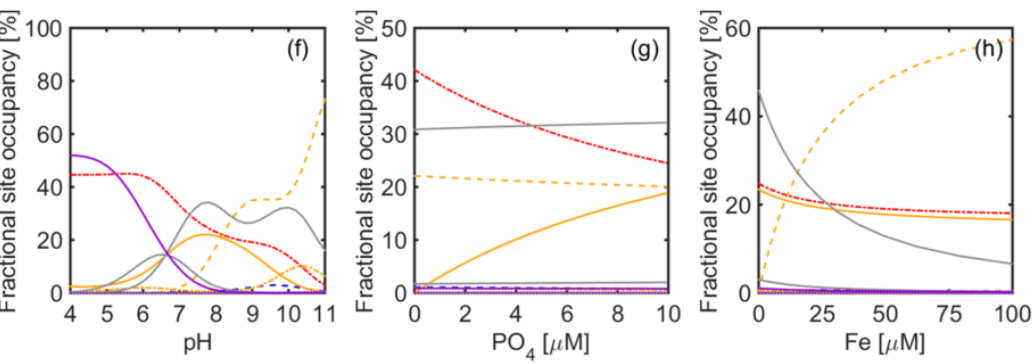

477 Fig. 5. Adsorption isotherms and effect of $\mathrm{pH}, \mathrm{PO}_{4}^{3-}$ and $\mathrm{Fe}$ on the surface composition

478 using the groundwater chemistry of well $4-5$. The first and second rows show the results 479 for the CD-MUSIC and DDL models, respectively.

480 The As isotherms shown in Fig. 5a and Fig. 5e are similar for both SCMs. However, the

481 DDL model generally shows higher As uptake for lower aqueous As concentrations (i.e., 482 As $<4-8 \mu \mathrm{M})$ and faster surface site saturation for increasing aqueous As concentration. 483 Furthermore, adsorption of As(III) is only predicted by the CD-MUSIC model and 484 exclusively occurs as goethite-Fe(II)-As(III) under any tested conditions. This complex is 485 favored under higher As(III) aqueous concentrations as well as mildly basic conditions 486 with a maximum at $\mathrm{pH} 9$ similar to the As(III) complexation in absence of $\mathrm{Fe}$ (II) 487 (Stachowicz et al., 2008). In both SCMs, the adsorption of As(V) occurs over the entire $488 \mathrm{pH}$ range and increases with more acidic conditions (Fig. 5b and Fig. 5f) in agreement 489 with the findings of Dixit and Hering (2003) and Stachowicz et al. (2006). Under the 490 typical $\mathrm{pH}$ range of natural water [6 - 9], the CD-MUSIC calculations indicate that As(V) 
491 complex occurs as the non-protonated bidentate complex $(\equiv \mathrm{FeO})_{2} \mathrm{AsO}_{2}^{-2}[50-80] \%$ and

492 to a lower extent as $\equiv \mathrm{FeOAsO}_{2} \mathrm{OH}^{-1.5}[20-50] \%$. Similarly, the DDL suggests a

493 dominance of $\equiv \mathrm{GoeAsO}_{4}^{-2}$ which is the surface species equivalent to the CD-MUSIC

494 model complex $(\equiv \mathrm{FeO})_{2} \mathrm{AsO}_{2}^{-2}$.

495 Besides the strong effect of $\mathrm{pH}$ on As adsorption, both SCMs show that a change in $\mathrm{pH}$

496 exerts a primary control on the overall surface composition with a non-linear effect on

497 sorption competition and change in speciation of the surface species (Fig. 5b and 5f).

498 However, significant discrepancies in the change of surface composition can be pointed

499 out between the SCMs in particular regarding the behavior of $\mathrm{As}$ and $\mathrm{PO}_{4}^{3-}$. For instance,

500 at low $\mathrm{pH}$, the computed As surface concentrations are significantly different (i.e., CD-

501 MUSIC model: $20 \mathrm{mmol} / \mathrm{kg}$, DDL model: $75 \mathrm{mmol} / \mathrm{kg}$ in well $4-5$ at $\mathrm{pH} 4$ ). Furthermore,

$502 \mathrm{PO}_{4}^{3-}$ and $\mathrm{As}(\mathrm{V})$ adsorption have similar behavior but the surface concentration of $\mathrm{PO}_{4}^{3-}$ is

503 significantly higher than As over the range of tested $\mathrm{pH}$ in the CD-MUSIC model. A

504 notable difference between the CD-MUSIC and the DDL models is that $\mathrm{PO}_{4}^{3-}$ adsorption

505 is shown to only occur at circumneutral $\mathrm{pH}$ by the DDL while the CD-MUSIC shows

506 high sorption of phosphate also under acidic conditions.

507 For both $\mathrm{SCMs}, \mathrm{PO}_{4}^{3-}$ is shown to be the major competitor for As sorption sites. The

508 release of $\mathrm{As}(\mathrm{V})$ is inversely proportional to the uptake of $\mathrm{PO}_{4}^{3-}$; however, phosphate does

509 not have a significant effect on the sorption of As(III), which exclusively occurs as the

510 ternary complex goethite-Fe(II)-As(III) (Fig. 5c and Fig. 5g). For well 4-5, an increase in 
$511 \mathrm{PO}_{4}^{3-}$ from 0 to $10 \mu \mathrm{M}$ causes a decrease of the $\mathrm{As}(\mathrm{V})$ surface concentration by 50

$512 \mathrm{mmol} / \mathrm{kg}$ and $25 \mathrm{mmol} / \mathrm{kg}$ in the CD-MUSIC and the DDL model, respectively.

513 In both SCMs, the change in Fe(II) concentration does not affect significantly As(V)

514 sorption. However, increasing Fe(II) concentration enhance the complexation of As(III)

515 as the goethite-Fe(II)-As(III) complex. In particular for well 4-5, increasing Fe(II) from 0

516 to $100 \mu \mathrm{M}$ brings the $\mathrm{As}$ (III) surface concentration to $70 \mathrm{mmol} / \mathrm{kg}$. In the DDL model,

517 iron is shown to mainly compete with $\mathrm{Mg}^{2+}$ whereas in the CD-MUSIC model, the 518 increase of Fe primarily leads to the decrease in protonated sites.

\section{$519 \quad 3.3 .2$. Effects of major ions}

520 Major ions have been shown to significantly influence sorption competition processes

521 through direct competition for sorption sites (Hayes and Leckie, 1987; Stachowicz et al., 522 2007; Geelhoed et al., 1997) and/or by modifying the mineral surface charge leading to

523 an enhancement in the adsorption of opposite charged species via electrostatic

524 interactions (Stachowicz et al., 2008). The second mechanism is addressed in the CD-

525 MUSIC description of surface complexation by the explicit consideration of the outer-

526 sphere complexes together with the definition of the triply coordinated group and

527 electrostatic 1-plane controlling the charge interactions between cations and anions.

528 Therefore, we tested the effect of $\mathrm{Ca}^{2+}, \mathrm{Mg}^{2+}, \mathrm{HCO}_{3}^{-}$and $\mathrm{SO}_{4}^{2-}$ on As desorption from

529 goethite and their impact on the surface composition using the CD-MUSIC model. A

530 brief comparison with the DDL model results is given in Section EA-4 in the Electronic 531 Annex. 
532 Figure 6 shows the simulated As desorption for the in-situ experiments when varying

533 individually the major ion concentrations over a range of values relevant for natural

534 groundwater (i.e., $[0.1-10] \mathrm{mM}$ for $\mathrm{Ca}^{2+}, \mathrm{Mg}^{2+}$ and $\mathrm{SO}_{4}^{2-}$ and $[0.1-20 \mathrm{mM}]$ for $\mathrm{HCO}_{3}^{-}$).

535 Additionally, a series of batch calculations with varying concentrations of major ions was

536 performed in order to interpret the results of the flow-through system.
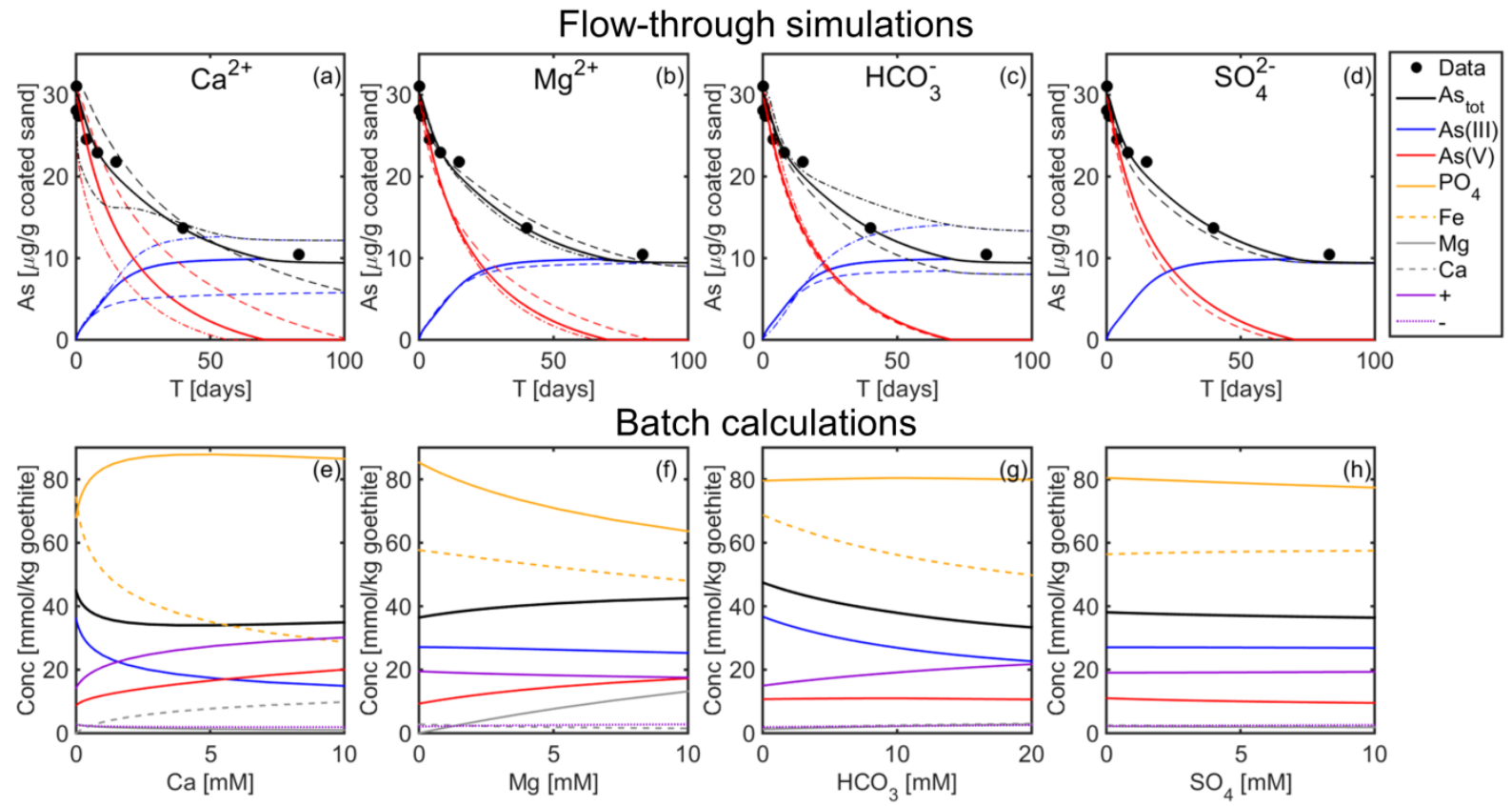

538 Fig. 6. Effect of the major ions on the As sorption behavior simulated using the CD-

539 MUSIC model under the hydrochemical conditions of well 4-5. (a) to (d): Flow-through

540 simulations, the full lines refer to the simulation performed considering groundwater

541 chemistry of well 4-5; dashed-dotted and dotted lines refer to the simulation results

542 obtained with the lowest and the highest values of the tested concentrations, respectively.

543 (e) to (h): Batch calculations spanning the range of variation of the major cations and 544 anions. 
545 Calcium is shown to have the highest effect on the surface composition and, in particular,

546 on As desorption among the considered major ions (Fig. 6a). An increase in $\mathrm{Ca}^{2+}$

547 concentration results in a higher uptake of $\mathrm{As}(\mathrm{V})$ and phosphate and reduces the

548 formation of $\mathrm{Fe}$ (II) and $\mathrm{As}(\mathrm{III})-\mathrm{Fe}(\mathrm{II})$ complexes. The effect of a change in $\mathrm{Ca}^{2+}$ on the

549 total As concentration is shown to be particularly strong in the batch system (Fig. 6e) at

550 lower calcium concentrations $(<2 \mathrm{mM})$, with a significant decrease in $\mathrm{As}(\mathrm{III})-\mathrm{Fe}(\mathrm{II})$

551 uptake. Regarding the simulation of in-situ experiments performed with the lowest $\mathrm{Ca}^{2+}$

552 concentration (i.e., $0.1 \mathrm{mM})$, the combined enhanced decrease in $\mathrm{As}(\mathrm{V})$ and the

553 stimulated uptake of As(III) result in a complex pattern of total As desorption. The

554 simulated curve (black dotted line in Fig. 6a) shows an S-shape with an initial steep slope

555 followed by a plateau regime at about 20 days.

556 Conversely, a change in the aqueous concentration of $\mathrm{Mg}^{2+}$ has little effect on arsenic

557 desorption as shown by the minimal variation of the simulated curves for the in-situ flow-

558 through systems (Fig. 6b). The detailed batch simulations (Fig. 6f) show no effect on the

559 goethite-Fe(II)-As(III) complex and surface protonation, and only a slight decrease in the

$560 \mathrm{Fe}(\mathrm{II})$ surface concentration likely due to sorption competition. To a lower extent than

$561 \mathrm{Ca}^{2+}$, higher $\mathrm{Mg}^{2+}$ concentrations enhance the uptake of $\mathrm{As}(\mathrm{V})$ (i.e., $+8 \mathrm{mmol} / \mathrm{kg}$ as

$\left.562(\equiv \mathrm{FeO})_{2} \mathrm{AsO}_{2}^{-2}\right)$ surface concentrations whereas it decreases significantly the phosphate

563 adsorption (i.e., $-20 \mathrm{mmol} / \mathrm{kg}$ ) as shown in the batch calculations (Fig. 6f).

564 Bicarbonate has an effect on arsenic sorption mainly through its impact on the solution

$565 \mathrm{pH}$ (Fig. 5). In these simulations, in which $\mathrm{pH}$ was fixed at the measured value of 8.1 in

566 well 4-5, the influence of changing $\mathrm{HCO}_{3}^{-}$concentrations is limited (Fig. 6c and Fig. 6g). 
567 The model results suggest that bicarbonate has little to no effect on the As(V) adsorption

568 whereas an increase in the bicarbonate concentrations is shown to lower the adsorption of

569 the ternary complex goethite-Fe(II)-As(III) and $(\equiv \mathrm{FeOH})_{2} \mathrm{Fe}^{+}$.

570 The CD-MUSIC model results show that sulfate has low to negligible influence on

571 arsenic desorption and on the surface composition. These outcomes are in agreement with

572 the findings of Geelhoed et al. (1997).

\section{4. Discussion}

574 The interpretation of the in-situ experiments highlighted discrepancies between the CD-

575 MUSIC and the DDL models. These outcomes and additional tests on established

576 laboratory datasets (Electronic Annex) showed an improved capability of the CD-MUSIC

577 in modeling As sorption onto goethite in complex multicomponent systems. The

578 limitations of the DDL model can be ascribed to the lower structural model complexity

579 relative to the description of the surface electrostatic behavior, as well as to the quality of

580 the sorption reaction database.

581 Besides assessing the SCMs ability to reproduce the arsenic desorption trends at the field

582 site, simulations were also performed to assess the impact of varying hydrochemical

583 conditions. The outcomes of the simulations show that the change in As surface

584 concentration mainly results from (i) the surface competition between $\mathrm{PO}_{4}^{3-}$ and $\mathrm{As}(\mathrm{V})$

585 and (ii) the As(III) sorption through the complex goethite-Fe(II)-As(III). The sensitivity

586 analysis also highlights the prominent effect of the groundwater chemistry on the surface

587 composition. Many aqueous species play an important role on the extent and rate of As

588 desorption. Their effects are typically complex and nonlinear and might not be directly 
589 visible from the data and forward simulations of field experiments. In particular, the

590 outcomes of the CD-MUSIC model suggest important implications of the major ions on

591 As mobility through the formation of outer-sphere complexes. Such complexes influence

592 the surface charge behavior and ultimately the sorption of trace elements. The performed

593 simulations helped us to disentangle such complex multicomponent effects and to

594 illuminate the important role of $\mathrm{pH}, \mathrm{PO}_{4}^{3-}$ and $\mathrm{Ca}^{2+}$ and, to a lower extent of $\mathrm{Mg}^{2+}$ and

$595 \mathrm{HCO}_{3}^{-}$, on As sorption on goethite

596 For instance, synergic effects between $\mathrm{Ca}^{2+}, \mathrm{PO}_{4}^{3-}$ and $\mathrm{As}$ were observed based on the 597 modeling of these in-situ experiments, in agreement with previous observations of such 598 interactions in laboratory setups (Stachowicz et al., 2008). Another interesting insight

599 from the performed simulations is the simultaneous increases in $\mathrm{As}$ and $\mathrm{PO}_{4}^{3-}$ surface 600 concentrations when increasing $\mathrm{Ca}^{2+}$ in the groundwater. Such a behavior may seem 601 counter-intuitive as $\mathrm{PO}_{4}^{3-}$ is expected to be the main competitor for $\mathrm{As}(\mathrm{V})$ sorption sites.

602 However, this result can be interpreted through the leading effect of a higher positive 603 charge in the 1-plane introduced by the inner and outer-sphere complexes of $\mathrm{Ca}^{2+}$

604 (Stachowicz et al., 2008) resulting in a higher surface affinity for $\mathrm{As}(\mathrm{V})$ and $\mathrm{PO}_{4}^{3-}$ having 605 both negative charges (i.e., $\Delta_{\mathrm{z}_{1}}=-1.47$ for the dominant $\mathrm{As}(\mathrm{V})$ surface species; $\Delta_{\mathrm{z}_{1}}=-$ $606 \quad 1.46$ and -1.28 for the main phosphate species under the considered aqueous conditions $607(\equiv \mathrm{FeOH})_{2} \mathrm{PO}_{2}^{-2}$ and $\left.\mathrm{FeOPO}_{2} \mathrm{OH}^{-1.5}\right)$. Indeed, higher $\mathrm{Ca}^{2+}$ concentrations result in 608 significantly higher surface charge density in the 1-plane that is compensated by a 609 decrease in surface charge density on the 0-plane (Figure EA14a in the Electronic 
610 Annex). Thus, the model suggests that, for the considered hydrochemical conditions, this

611 electrostatic effects can hamper the sorption competition between $\mathrm{As}(\mathrm{V})$ and $\mathrm{PO}_{4}^{3-}$.

612 Furthermore, our modeling results indicate significant inverse effect of $\mathrm{Ca}^{2+}$ on the $\mathrm{Fe}$

613 complexes and in particular on the ternary complex goethite-Fe(II)-As(III). The presence

614 of $\mathrm{Ca}^{2+}$ introduces a higher positive charge in the 1-plane and limits, by electrostatic

615 repulsion, the formation of the Fe(II)-As(III) surface complex $\left(\Delta_{z_{1}}=0.92\right)$ and the Fe

616 surface complex $\left(\Delta_{\mathrm{z}_{1}}=1.27\right)$. In contrast, Stachowicz et al. (2008) observed an increase

617 in the adsorption of $\mathrm{As}(\mathrm{III})$ in the presence of $\mathrm{Ca}^{2+}$ in dual-adsorbate experiments due to

618 their opposite charges. Thus, besides the potential oxidation of As(III) occuring through

619 the formation of the ternary complex goethite-Fe(II)-As(III), the latter exhibits an

620 opposite surface charge behaviour than single As(III) complexes.

621 As indicated by the CD-MUSIC model, the presence of dissolved ferrous iron seems to

622 be particularly important under the in-situ conditions by primarily enhancing the As(III)

623 adsorption whereas the complex hydrochemistry of the groundwater appears to prevent

624 the direct sorption of $\mathrm{As}(\mathrm{III})$ onto goethite. In particular, $\mathrm{PO}_{4}^{3-}$ is known to strongly

625 compete for As(III) sorption sites (Stachowicz et al., 2008) while the CD-MUSIC model

626 based on the field data indicates that the effect of $\mathrm{PO}_{4}^{3-}$ on the goethite-Fe(II)-As(III)

627 complex is negligible. Specifically, the highest As surface concentration at 80 days was

628 measured in well 4-5 with the highest $\mathrm{PO}_{4}^{3-}$ concentration. 
630 Regarding $\mathrm{Mg}^{2+}$, Stachowicz et al. (2008) observed similar surface interaction with trace

631 compounds in dual-sorbate system, when compared to $\mathrm{Ca}^{2+}$, due to induced charge

632 effects and successfully captured the sorption processes with the CD-MUSIC model.

633 Using the same description of the surface chemical reactions in our model, an increase in

$634 \mathrm{Mg}^{2+}$ uptake is shown to conversely lower the $\mathrm{PO}_{4}^{3-}$ adsorption and, consequently, to

635 favor the As(V) adsorption under the field hydrochemical conditions of the present study.

636 This disagreement about the influence of $\mathrm{Mg}^{2+}$ on the adsorption mechanisms can be

637 ascribed to the difference in the electrolyte solutions. For the groundwater solution,

638 containing a larger variety and amount of major ions, the influence of $\mathrm{Mg}^{2+}$ on the

639 surface charge is shown to be hindered (Figure EA14b in the Electronic Annex).

640 The role of bicarbonate on As desorption from Fe-oxides has been a matter of debate

641 (Appelo et al., 2002; Stachowicz et al., 2007; Radu et al., 2005; Rahnemaie et al., 2007;

642 Stachowicz et al., 2007). Our modeling results suggest that $\mathrm{HCO}_{3}^{-}$has negligible effects

643 on the $\mathrm{As}(\mathrm{V})$ adsorption under the environmental hydrochemical conditions at this field

644 site. However, $\mathrm{HCO}_{3}^{-}$is shown to lower the adsorption of the ternary complex goethite-

$645 \mathrm{Fe}(\mathrm{II})-\mathrm{As}(\mathrm{III})$ and $(\equiv \mathrm{FeOH})_{2} \mathrm{Fe}^{+}$although this effect primarily results from the increase

646 in surface site protonation similar to the effect of a change in $\mathrm{pH}$ on the change in surface

647 composition (Fig. 6c and Fig. 6g).

648 Despite the complex interplay between many aqueous species taking place in sorption 649 processes, the outcomes of surface complexation modeling can be used to interpret the 650 impact of groundwater hydrochemistry on arsenic transport and mobility in As651 contaminated reducing groundwaters. Table 1 reports the concentrations of important 
652 groundwater species as well as the As surface concentrations on goethite simulated with 653 the CD-MUSIC model for the field groundwater conditions from well 4-5 as well as 654 reported in two previous studies (Jessen et al., 2012; Biswas et al., 2014). In those 655 contributions, CD-MUSIC simulations were performed to help understanding field 656 observations by considering the surface interactions between groundwater species and 657 sedimentary Fe-oxides and showed that the complexation of goethite-Fe(II)-As(III) was 658 the dominant mechanism of As(III) uptake in the Red River flood plain (Jessen et al., 659 2012) and in the Bengal Basin (Biswas et al., 2014). Regarding the in-situ hydrochemical 660 conditions of the present study, the maximum remaining As surface concentrations (9.55 $661 \mu \mathrm{g} / \mathrm{g}$ compared to an average of $3.32 \mu \mathrm{g} / \mathrm{g}$ ) was detected in well 4-5, in which the highest 662 pH (i.e., 8.1) was measured. In comparison, Jessen et al. (2012) and Biswas et al. (2014) 663 simulated lower As(III) surface concentration for goethite at equilibrium with 664 groundwater having circumneutral $\mathrm{pH}$ and higher $\mathrm{Ca}^{2+}$ concentrations which represent 665 hydrochemical conditions that are less favorable for the formation of the goethite-Fe(II)666 As(III) as shown in Section 3.3. Surface composition calculation of goethite using the 667 groundwater composition of well 4-5 and applying similar goethite concentration (i.e., $6680.3 \mathrm{mmol}$ sites/L) to Jessen et al. (2012) and Biswas et al. (2014) did not lead to 669 significant change in the surface coverage of As. Conversely, when changing $\mathrm{pH}$ to 7 , 670 significantly less As(III) uptake was obtained (i.e., $1.34 \%$ ) similarly to the surface sites 671 occupancy found in the studies of Jessen et al. (2012) and Biswas et al. (2014) despite the 672 substantially higher As(III) concentrations in well 4-5. Thus, $\mathrm{pH}$ is likely to represent a 673 determining parameter for the mobility of As(III) through the formation of the complex 674 goethite-Fe(II)-As(III). Furthermore, the concentrations of Fe(II) reported in Jessen et al. 
675 (2012) and Biswas et al. (2014) are significantly higher than in well 4-5 suggesting that

676 uptake of As(III) might remain significant at low Fe level as shown in Section 3.3.1.

677

678 Table 1: Comparison of the concentrations of relevant aqueous species and resulting

$679 \mathrm{As}(\mathrm{V})$ and $\mathrm{As}(\mathrm{III})$ fractional site occupancies on goethite at equilibrium simulated with

680 the CD-MUSIC model in different studies.

\begin{tabular}{l|ccc} 
Location & $\begin{array}{c}\text { This study (well 4-5) } \\
\text { Hetao Basin }\end{array}$ & $\begin{array}{c}\text { Biswas et al. (2014) } \\
\text { Bengal Basin }\end{array}$ & $\begin{array}{c}\text { Jessen et al. (2012) } \\
\text { Red River flood plain }\end{array}$ \\
\hline$[\mathrm{mmol}$ sites /L] & 5.73 & 0.24 & 0.31 \\
\hline $\mathrm{pH}$ & 8.1 & 7.2 & 6.98 \\
$\mathrm{As}(\mathrm{III})[\mu \mathrm{g} / \mathrm{L}]$ & 535 & 138 & 187 \\
$\mathrm{As}(\mathrm{V})[\mu \mathrm{g} / \mathrm{L}]$ & 5.75 & 10 & 44.95 \\
$\mathrm{PO}_{4}^{3-}[\mu \mathrm{g} / \mathrm{L}]$ & 382 & 260 & 759.76 \\
$\mathrm{Fe}(\mathrm{II})[\mathrm{mg} / \mathrm{L}]$ & 0.19 & 5 & 10.42 \\
$\mathrm{HCO}_{3}^{-}[\mathrm{mg} / \mathrm{L}]$ & 623 & 480 & 537 \\
$\mathrm{Ca}^{2+}[\mathrm{mg} / \mathrm{L}]$ & 23 & 90 & 112.22 \\
$\mathrm{Mg}^{2+}[\mathrm{mg} / \mathrm{L}]$ & 30.1 & 25 & 31.59 \\
\hline $\mathrm{As}^{2}(\mathrm{~V})[\%]$ & 7.3 & 0 & 6 \\
$\mathrm{Fe}(\mathrm{II})-\mathrm{As}(\mathrm{III})[\%]$ & 6.3 & 1.4 & 2
\end{tabular}

681

682 4.1. Global sensitivity

683 Finally, in order to illustrate the relative linear and non-linear effects of the individual

684 aqueous species on arsenic sorption, we have performed a global sensitivity analysis by

685 applying the Morris method to the field As desorption models of the 7 different wells.

686 Using this approach, two model estimates are obtained: (i) $\mu$ expresses the overall

687 importance of the model parameters on the model output; (ii) $\sigma$ expresses the non-linear

688 effects of the tested parameters and their mutual interactions. 
CD-MUSIC
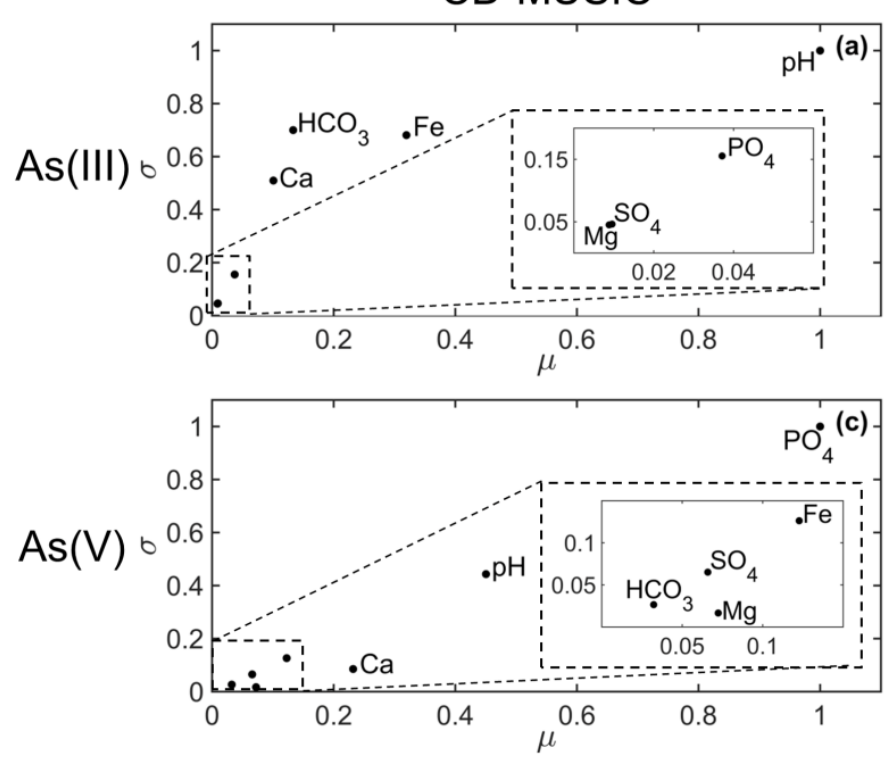
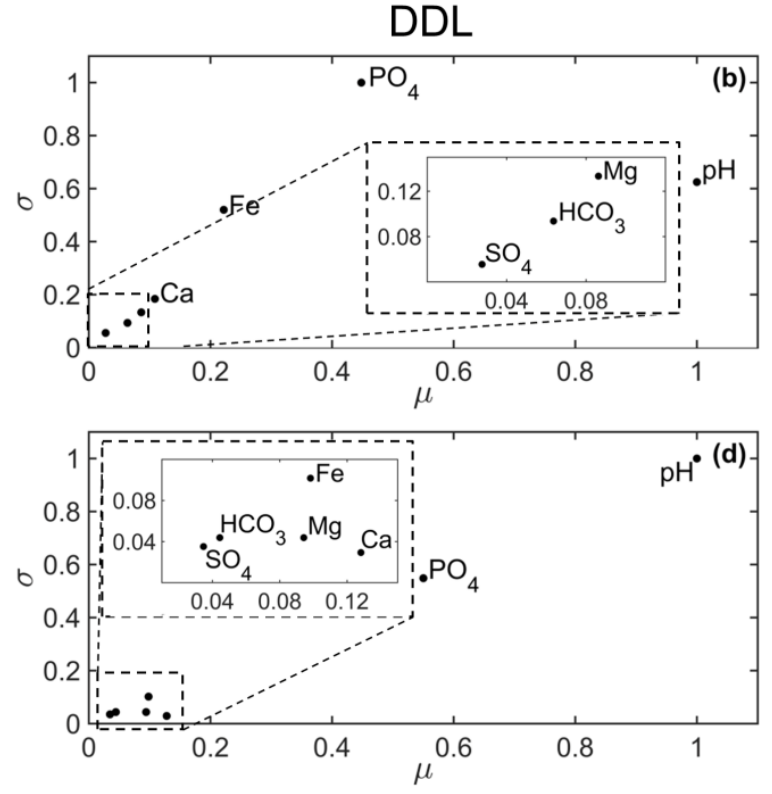

690 Fig. 7. Relative importance of $\mathrm{pH}, \mathrm{PO}_{4}^{3-}, \mathrm{Fe}, \mathrm{Ca}^{2+}, \mathrm{Mg}^{2+}, \mathrm{HCO}_{3}^{-}$and $\mathrm{SO}_{4}^{2-}$ on the

691 adsorption/desorption of the As species onto goethite.

692 The results of the global sensitivity analysis are shown in Figure 7 and can be 693 summarized in the following points:

- $\mathrm{As}(\mathrm{V})$ sorption is shown to be predominantly controlled by $\mathrm{pH}$ and $\mathrm{PO}_{4}^{3-}$ although

695 it can be noted that the CD-MUSIC model slightly differ from the DDL model as it indicates a stronger effect of $\mathrm{PO}_{4}^{3-}$ on $\mathrm{As}(\mathrm{V})(\mathrm{Fig} .7 \mathrm{c}$ and $7 \mathrm{~d})$. contrast, $\mathrm{PO}_{4}^{3-}$ has a negligible influence in the CD-MUSIC (Fig 7a) which simulate the sorption of $\mathrm{As}(\mathrm{III})$ as goethite-Fe(II)-As(III). Conversely, in the DDL model $\mathrm{PO}_{4}^{3-}$ seems to have a significant effect on the As(III) uptake although, as 
shown in Section 3.3, this surface complexation model shows very low adsorption of As(III) for the considered hydrochemical conditions.

- Fe has a significant effect on the As(III) adsorption for both SCMs (Fig 7a and 7b) whereas it doesn't influence the As(V) sorption (Fig. 7c and 7d).

- The major ions are also shown to have negligible influence on the As sorption in the DDL model whereas some of these species are shown to play an important role by the CD-MUSIC model. For instance, $\mathrm{Ca}^{2+}$ influences the sorption of $\mathrm{As}(\mathrm{III})$ and $\mathrm{As}(\mathrm{V})$ (Fig. 7a and $7 \mathrm{~b}$ ) and $\mathrm{HCO}_{3}^{-}$is shown to exert a control on the sorption of As(III) (Fig. 7a).

- None of the tested species is shown to have purely linear or non-linear effects on

711 the As desorption, although non-linear effects of $\mathrm{HCO}_{3}^{-}$and $\mathrm{Ca}^{2+}$ on the sorption 712 of As(III) seems to be more pronounced (Fig. 7a).

\section{5. Conclusions}

715 In this study, we compared the capabilities of two common SCMs (i.e., the DDL and the

716 CD-MUSIC models) to simulate the arsenic desorption from synthetized goethite-coated

717 sand under natural hydrochemical conditions monitored in a reducing As-contaminated

718 aquifer with respect to the complex interactions occurring at the solution-mineral

719 interface. The focus was on a partially controlled system involving a well-known

720 synthetic mineral phase but natural groundwater chemistry and, thus, complex

721 multispecies interactions in the pore water and at the surface/solution interface. The

722 modeling of such system, of intermediate complexity compared to traditional laboratory 
723 experiments and field investigations, can provide important insights on the factors

724 influencing the mobility of As in groundwater.

725 Arsenic field desorption at the 7 spatial locations of the considered in-situ experiment 726 was successfully simulated with a modeling approach considering flow-through

727 conditions, surface complexation and groundwater hydrochemistry. Parallelization and 728 optimization of the simulations allowed us to obtain a single set of parameters for all

729 observation wells. The proposed approach is a valuable tool that can be exported to other 730 field sites with different groundwater conditions. Using the dataset of the in situ 731 experiments performed in the Hetao basin (China), we demonstrated the capability of the

732 proposed modeling approach to reproduce arsenic concentrations measured at the surface

733 of goethite under natural hydrochemical conditions. However, the comparison between

734 the description of surface complexation reactions with CD-MUSIC and DDL

735 formulations highlights important differences between the two models for the considered

736 conditions. This suggests that the choice of the SCM can have important implications on

737 the interpretation of experimental observations and on the assessment of As mobility in

738 aquifer systems. In particular, the better agreement between the CD-MUSIC simulations

739 and the field observations at all considered spatial locations indicates the enhanced

740 capability of this SCM to describe the complex interactions between charged species at

741 the mineral/solution interface. This capability relates to the higher structural complexity

742 of the CD-MUSIC model that explicitly accounts for the multiple mineral surface

743 coordination groups and has a more comprehensive representation of the electrostatic

744 interaction at the mineral-solution interface. The CD-MUSIC surface reactions database

745 also seems more suitable for simulating the sorption processes at the goethite surface in 
746 natural hydrochemical systems due to its implementation based on experimental

747 observations of multicomponent systems.

748 Regarding the complex interplay between charged species in sorption processes, the

749 explicit consideration of direct and indirect effects from chemical and electrostatic

750 interactions is required to accurately assess and predict the mobility of contaminants in

751 the subsurface. To this end, SCMs represent a considerable progress in comparison to the

752 traditional empirical sorption modeling approaches; however, their implementation and

753 validation in complex multicomponent flow-through systems are still rare. This study has

754 focused on goethite but we think that the implementation of surface complexation

755 databases for other relevant mineral phases, with a careful assessment of their

756 performance in multicomponent systems, will be of primary importance to improve the

757 descriptions of the mechanisms of contaminant sorption and release. This will enhance

758 our capability to represent and capture the key role of electrostatic interactions between

759 charged groundwater constituents both at the surface-solution interface and within the

760 pore water (Hiemstra and van Riemsdijk, 1996; Stachowicz et al., 2008; Rolle et al.,

761 2013; Muniruzzaman and Rolle, 2015). The quantitative description of such important

762 mechanisms will strengthen our capability to assess contaminant release, transport, and

763 fate, in complex, multidimensional, physically and chemically heterogeneous

764 groundwater systems (Wang et al., 2018; Fakhreddine et al., 2016; Wen and Li, 2018; Ye

765 et al., 2015). 


\section{Acknowledgments}

769 This work was supported by the Sino-Danish Center for Education and Research (SDC)

770 with a PhD scholarship granted to L.S.; M.R. also acknowledges the support of the

771 Villum Block Fellowship (Villum Fonden, Denmark). Constructive comments of three 772 anonymous reviewers helped improving the quality of the manuscript.

773

774 References

775

776

777

778

779

780

781

782

783

784 Appelo C. and Postma D., 2005. Geochemistry, groundwater and pollution.. 2nd ed.

785 London: CRC Press.

786 Berg M., Trang P.T.K, Stengel C., Buschmann J., Viet P.H., Dan N.V., Giger W. and

787 Stüben D., 2008. Hydrological and sedimentary controls leading to arsenic contamination 788 of groundwater in the Hanoi area, Vietnam: The impact of iron-arsenic ratios, peat, river

789 bank deposits, and excessive groundwater abstraction. Chem. Geol., 249(1-2), 91-112.

790 Biswas A., Gustafsson, J.P., Neidhart H., Halder D., Kundu A.M., Chatterjee D., Berner, 791 Z. and Bhattacharya, P., 2014. Role of competing ions in the mobilization of arsenic in 792 groundwater of Bengal Basin: Insight from surface complexation modeling. Water Res., 793 55, 30-39. 
794 Bretzler A., Stolze L., Nikiema J., Lalanne F., Ghadiri E., Brennwald M.S., Rolle M., and

795 Schirmer M., 2018. Hydrogeochemical and multi-tracer investigations of arsenic-affected

796 aquifers in semi-arid West Africa. Geoscience Frontiers, 1-17

797 Charlton S. and Parkhurst D., 2011. Modules based on the geochemical model

798 PHREEQC for use in scripting and programming languages. Comput. Geosci., 37, 1653-

7991663.

800 Cornell R. and Schwertmann U., 2003. The iron oxides: structure, properties, reactions,

801 occurrence and uses. 2nd ed. Weinheim, Germany: VCH.

802 Davis J., Coston J., Kent D. and Fuller C., 1998. Application of the surface complexation

803 concept to complex mineral assemblages. Environ. Sci. Technol., 32(19), 2820-2828.

804 Davis J., James R. and Leckie J.O., 1978. Surface ionization and complexation at the

805 oxide/water interface. I. Computation of electrical double layer properties in simple

806 electrolytes. J. Colloid Interface Sci., 63(3), 480-499.

807 Davis J. and Kent D., 1990. Surface complexation modeling in aqueous geochemistry.

808 Reviews in Mineralogy, 23, 177-260.

809 Dixit S. and Hering J.G., 2003. Comparison of Arsenic(V) and Arsenic(III) sorption onto

810 iron oxide minerals: implications for arsenic mobility. Environ. Sci. Technol., 37(18),

811 4182-4188.

812 Dixit S. and Hering J.G., 2006. Sorption of Fe(II) and As(III) on goethite in single- and

813 dual-sorbate systems. Chem. Geol., 228, 6-15.

814 Dzombak D. and Morel F., 1990. Surface Complexation Modeling- Hydrous Ferric

815 Oxide. New York: Wiley.

816 Fakhreddine S, Lee J., Kitanidis P.K., Fendorf S. and Rolle M., 2016. Imaging

817 geochemical heterogeneities using inverse reactive transport modeling: An example

818 relevant for characterizing arsenic mobilization and distribution. Adv Water Resour., 88,

819 186-197.

820 Geelhoed J. S., Hiemstra T. and van Riemsdijk, W., 1997. Phosphate and sulfate

821 adsorption on goethite: Single anion and competitive adsorption. Geochim. Cosmochim.

822 Acta, 61(12), 2389-2396.

823 Goldberg S., 1992. Use of surface complexation models in soil and chemical systems.

824 Adv. Agro., 47, 233-329.

825 Guo H., Jia Y., Wanty R.B., Jiang Y., Zhao W., Xiu W., Shen J., Li Y., Cao Y., Wu Y., 826 Zhang D., Wie C., Zhang Y., Cao W. and Foster A., 2016. Contrasting distributions of 
827 groundwater arsenic and uranium in the western Hetao basin, Inner Mongolia:

828 Implication for origins and fate controls. Sci. Total Environ., 541, 1172-1190.

829 Guo H., Wen D., Liu Z., Jia Y. and Guo Q., 2014. A review of high arsenic groundwater

830 in Mainland and Taiwan, China: Distribution, characteristics and geochemical processes.

831 App. Geochem., 41, 196-217.

832 Guo H., Yang S., Tang X., Li Y. and Shen Z., 2008. Groundwater geochemistry and its

833 implications for arsenic mobilization in shallow aquifers of the Hetao Basin, Inner

834 Mongolia. Sci. Total Env., 393, 131-144.

835 Guo H., Zhang B., Wang G. and Shen Z., 2010. Geochemical controls on arsenic and rare

836 earth elements approximately along a groundwater flow path in the shallow aquifer of the

837 Hetao Basin, Inner Mongolia. Chem. Geol., 270, 117-125.

838 Gustafsson J. and Bhattacharya P., 2007. Chapter 6: Geochemical modelling of arsenic

839 adsorption to oxide surfaces. In: B. P., et al. eds. Arsenic in Soil and Groundwater

840 Environment. s.1.:Elsevier B.V., 159-206.

841 Haberer C., Muniruzzaman M., Grathwohl P. and Rolle M., 2015. Diffuse-dispersive and 842 reactive fronts in porous media. Vadoze Zone J., 14(5).

843 Hauduc H., Neumann M.B., Muschalla D., Gamerith V., Gillot S. and Vanrolleghem 844 P.A., 2015. Efficiency criteria for environmental model quality assessment: A review and 845 ist application to wastewater treatment. Env. Mod. Soft., 68, 196-204.

846 Hayes K.F., Redden G., Wendell E. and Leckie J.O., 1990. Surface complexation models: 847 An evaluation of model parameter estimation using FITQL and oxide mineral titration 848 data. J. Colloid Interf. Sci., 142(2), 448-469.

849 Hayes K. and Leckie J.O., 1987. Modeling ionic-strength effects on cation adsorption at 850 hydrous oxide-solution interfaces. J. Colloid Interf. Sci., 115(2), 564-572.

851 Hiemstra T., Barnett M. and van Riemsdijk W., 2007. Interaction of silicic acid with 852 goethite. J. Colloid Interf Sci., 310, 8-17.

853 Hiemstra T. and van Riemsdijk W., 1996. A surface structural approach to ion 854 adsorption: the charge distribution (CD) model. J. Colloid Interf. Sci., 179, 488-508.

855 Hiemstra T. and van Riemsdijk W., 2006. On the relationship between charge 856 distribution, surface hydration, and the structure of the interface of metal hydroxides. $J$. 857 Colloid Interf. Sci., 301, 1-18.

858 Hiemstra T. and van Riemsdijk W., 2007. Adsorption and surface oxidation of Fe(II) on 859 metal (hydr)oxides. Geochim Cosmochim. Acta, 71, 5913-5933. 
860 Jessen S., Postma D., Larsen F., Nhan P.Q., Hoa L.Q., Trang P.T.K., Long T.V., Viet 861 P.H. and Jakobsen R., 2012. Surface complexation modeling of groundwater arsenic 862 mobility: Results of a forced gradient experiment in a Red River flood plain aquifer, 863 Vietnam. Geochim. Cosmochim. Acta, 98, 186-201.

864 Jia Y., Guo H., Jiang Y., Wu Y. and Zhou Y., 2014. Hydrogeochemical zonation and its 865 implication for arsenic mobilization in deep groundwaters near alluvial fans in the Hetao 866 Basin, Inner Mongolia. J. Hydrol., 518, 410-420.

867 Johannesson K.H. and Neumann K., 2013. Geochemical cycling of mercury in a deep, 868 confined aquifer: Insights from biogeochemical reactive transport modeling. Geochim. 869 Cosmochim. Acta, 106, 25-43.

870 Kulkarni H. V., Mladenov N., Johannesson K.H. and Datta S., 2017. Contrasting 871 dissolved organic matter quality in groundwater in Holocene and Pleistocene aquifers and 872 implications for influencing arsenic mobility. Appl. Geochem., 77, 194-205.

873 Li L., Salehikhoo F., Brantley S. and Heidari P., 2014. Spatial zonation limits magnesic 874 dissolution in porous media. Geochim. Cosmochim. Acta, 126, 555-573.

875 Link D.D., Walter P.J., Kingston, H.M., 1998, Development and validation of the new 876 EPA Microwave-Assisted Leach Method 3051A. Env. Sci. Technol., 32, 3628-3632

877 Lowers H.A., Breit G.N., Foster A.L., Whitney J., Yount J., Uddin N. and Muneem A., 878 2007. Arsenic incorporation into authigenic pyrite, Bengal Basin sediment, Bangladesh. 879 Geochim. Cosmochim. Acta, 71, 2699-2717.

880 Mathur S. and Dzombak D., 2006. Chapter 16: Surface complexation modeling: Goethite. 881 In: J. Lutzenkirchen, ed. Surface Complexation Modeling 1st Edition. London: Elsevier 882 Ltd., 443 - 467.

883 Muniruzzaman M., Haberer C.M., Grathwohl P. and Rolle M., 2014. Multicomponent 884 ionic dispersion during transport of electrolytes in heterogeneous porous media: 885 Experiments and model-based interpretation. Geochim. Cosmochim. Acta, 141, 656-669.

886 Muniruzzaman M. and Rolle M., 2015. Impact of multicomponent ionic transport on $\mathrm{pH}$

887 fronts propagation in saturated porous media. Water Resour. Res., 51, 6739-6755.

888 Muniruzzaman M. and Rolle M., 2016. Modeling multicomponent ionic transport in 889 groundwater with IPhreeqc coupling: Electrostatic interactions and geochemical reactions 890 in homogeneous and heterogeneous domains. Adv. Water Resour., 98, 1-15.

891 Parkhurst, D. \& Appelo, C., 2013. Description of input and examples for PHREEQC

892 version 3 - A computer program fro speciation, batch-reaction, one-dimensional 
893 transport, and inverse geochemical calculations. In: U.S. Geological Survey Techniques

894 amd Methods. s.1.:s.n., 497.

895 Pedersen H.D., Postma D. and Jakobsen R., 2006. Release of arsenic associated with the

896 reduction and transformation of iron oxides. Geochim. Cosmochim. Acta, 70, 4116-4129.

897 Polizzotto M.L., Kocar B.D., Benner S.G., Sampson M. and Fendorf S., 2008. Near-

898 surface wetland sediments as a source of arsenic release to ground water in Asia. Nature, 899 454(July), 1-5.

900 Postma D., Larsen F., Thai N.T., Trang P.T.K., Jakobsen R., Nhan P.Q., Long T.V., Viet 901 P.H. and Murray A.S., 2012. Groundwater arsenic concentrations in Vietnam controlled 902 by sediment age. Nature Geosci., 5, 656-661.

903 Postma D., Larsen F., Jessen S., Hue N.T.M., Duc M.T., Viet P.H. and Nhan P.Q., 2007. 904 Arsenic in groundwater of the Red River floodplain, Vietnam: Controlling geochemical 905 processes and reactive transport modeling. Geochim. Cosmochim. Acta, 71(21), 50549065071.

907 Radu T., Subacz J., Phillippi J. and Barnett M., 2005. Effects of dissolved carbonate on 908 arsenic adsorption and mobility. Environ. Sci. Technol., 39, 7875-7882.

909 Rahnemaie R., Hiemstra T. and van Riemsdijk W., 2006. Inner- and outer-sphere

910 complexation of ions at the goethite-solution interface. J. Colloid Interf. Sci., 297, 379911388.

912 Rahnemaie R., Hiemstra T. and van Riemsdijk W., 2007. Carbonate adsorption on

913 goethite in competition with phosphate. J. Colloid Interf. Sci., 315, 415-425.

914 Rathi B., Neidhart H., Berg M., Siade A. and Prommer H., 2017. Processes governing 915 arsenic retardation on Pleistocene sediments: Adsorption experiments and model-based 916 analysis. Water Resour. Res., 53(5), 4344-4360.

917 Rawson J., Prommer H., Siade A., Carr J., Berg M., Davis J. and Fendorf S., 2016.

918 Numerical modeling of arsenic mobility during reductive iron-mineral transformations.

919 Environ. Sci. Technol., 50(5), 2459-2467.

920 Rodríguez-lado, L., Sun, G., Berg, M., Zhang, Q., Xue, H., Zheng, Q., Johnson, A., 2013.

921 Groundwater arsenic contamination throughout China. Science, 341, 866-869.

922 Rolle M., Muniruzzaman M., Haberer C. and Grathwohl P., 2013. Coulombic effects in 923 advection-dominated transport of electrolytes in porous media: Multicomponent ionic 924 dispersion. Geochim. Cosmochim. Acta, 120, 195-205. 
925 Rolle M., Sprocati R., Masi M., Jin B. and Muniruzzaman M., 2018. Nernst-Planck based 926 description of transport, coulombic interactions and geochemical reactions in porous

927 media: modeling approach and benchmark experiments. Water Resour. Res., 54(4), 31769283195.

929 Saltelli A., Tarantola S., Campolongo F. and Ratto M., 2004. Sensitivity Analysis in 930 Practice: A Guide to Assessing Scientific Models. s.1.:John Wiley and Sons.

931 Sharma P., Rolle M., Kocar B., Fendorf S. and Kappler A., 2011. Influence of natural 932 organic matter on As transport and retention. Environ. Sci. Technol., 45, 546-553.

933 Smedley P. and Kinniburgh D., 2002. A review of the source, behaviour and distribution 934 of arsenic in natural waters. Appl. Geochem., 17, 517-518.

935 Smith R. and Martell A., 1976. Critical Stability Constants. Volume 4: Inorganic 936 complexes. 1st ed. New York: Springer Science+Business Media.

937 Sohier H., Farges J. and Pet-Lahanier H., 2014. Improvement of the representativity of 938 the Morris method for air-launch-to-orbit separation. Proceedings of the 19th World 939 Congress The International Federation of Automatic Control Cape Town, South Africa, 940 7954-7959.

941 Stachowicz M., Hiemstra T. and van Riemsdijk W., 2008. Multi-competitive interactin of $942 \mathrm{As}(\mathrm{III})$ and $\mathrm{As}(\mathrm{V})$ oxyanions with $\mathrm{Ca}^{2+}, \mathrm{Mg}^{2+}$, and $\mathrm{CO}_{3}^{2-}$ ions on goethite. J. Colloid 943 Interface Sci, 320, 400-414.

944 Stachowicz M., Hiemstra T. and van Riemsdijk W., 2006. Surface speciation of As(III) 945 and As(V) in relation to charge distribution. J. Colloid Interf. Sci., 302, 62-75.

946 Stachowicz M., Hiemstra T. and van Riemsdijk W., 2007. Arsenic-bicarbonate 947 interaction on goethite particles. Environ. Sci. Technol., 41, 5620-5625.

948 Stollenwerk K., Breit G.N., Welch A.H., Yount J.C., Whitney J.W., Forster A.L., Uddin 949 M.N., Majumder R.K. and Ahmed N., 2007. Arsenic attenuation by oxidized sediments 950 in Bengladesh. Sci. Tot. Environ., 379, 133-150.

951 Tufano K. and Fendorf S., 2008. Confounding impacts of iron reduction on arsenic 952 retention. Environ. Sci. Technol., 42(13), 4777-4783.

953 Van Geen A., Robertson A. and Leckie J.O., 1994. Complexation of carbonate species at 954 the goethite surface: Implications for adsorption of metal ions in natural waters. Geochim. 955 Cosmochim. Acta, 58(9), 2073 - 2086.

956 Wang L., Wen H. and Li L., 2018. Scale dependence of surface complexation capacity 957 and rates in heterogeneous media. Sci. Total Environ., 635, 1547-1555. 
958 Wen H. and Li L., 2018. An upscaled rate law for mineral dissolution in heterogeneous 959 media: The role of time and length scales. Geochim. Cosmochim Acta, 235, 1-20.

960 Ye Y., Chiogna G., Cirpka O.A., Grathwohl P., Rolle M., 2015. Enhancement of plume 961 dilution in two-dimensional and three-dimensional porous media by flow focusing in

962 high-permeability inclusions. Water Resour. Res., 51, 1-21.

963 Zhang D., Guo H., Xiu W., Ni P., Zheng H. and Cao W., 2017. In-situ mobilization and 964 transformation of iron oxides-adsorbed arsenate in natural groundwater. J. Hazard.

965 Mater., 321, 228-237.

966 